\title{
CONDENSATION OF WATER FROM ENGINE EXHAUST FOR AIRSHIP BALLASTING ${ }^{1}$
}

\author{
By Robert F. Kohr
}

\section{ABSTRACT}

The operation of airships involves the maintenance of approximate equilibrium during flight. The craft must be neither greatly heavier nor greatly lighter than the air it displaces. Perhaps the greatest cause of static unbalance is consumption of fuel by the engines. This has been compensated in the past by releasing enough lifting gas to maintain equilibrium.

The use of helium, on account of its scarcity and high cost, makes imperative some less wasteful means of decreasing the lift. This paper describes the method by which this has been accomplished, namely, the condensation of a large part of the water vapor formed during combustion by the combination of oxygen of the air with hydrogen of the fuel. The condensation is accomplished by cooling the exhaust gas in a bank of thin-walled tubes suspended in the air stream. Some of the condensed water remains in the form of spray and is collected by passing the cooled gas through a baffle-type separator. The amount of water present in the exhaust gas is influenced by the kind of fuel, ratio of air to fuel in the mixture supplied the engine, and the humidity of the entering air. The effect of these variables is presented in the form of tables and curves.

The performance of the apparatus during both ground and flying tests is summarized and suggestions made regarding possible improvements.

The heat-transfer process involved in the air-cooled condenser used is described in detail, and a sample design is carried through to illustrate the method of determining the necessary length of the condensing apparatus.

\section{CONTENTS}

Part I.-General__.

I. Introduction

II. Previous work _. 539

III. Summary of work at the Bureau of Standards $\ldots 540$

1. Ground tests

2. Flying test_... 543

IV. Description of condensers

V. Separators

VI. Ground test results, Model I._. 546

VII. Ground test results, Model II _._.

VIII. Flying test results

IX. Conclusions

1 The work described in this paper was undertaken by the Bureau of Standards at the request and with the support of the United States Army Air Service in September, 1920. A more detailed description of the apparatus with drawings of the parts forms a part of an Air Service Information Circular (Aerostation), Vol. I, No. 44, dated May 1, 1924, by the same author. It is not felt that such information is of sufficient general interest to warrant its inclusion in this paper. 
Page

Part II.-Theory

I. Nomenclature

II. Design considerations._.

III. Effect of fuel composition _._.

IV. Mixture ratio _. 560

V. Humidity _.

VI. Heat transfer.

Part III.-Sample design

\section{Part I-GENERAL}

\section{INTRODUCTION}

The maintenance of a constant total lift in lighter-than-air craft falls naturally into two distinct divisions: (1) Recovery of ballast as the consumption of fuel tends to lighten the ship. (2) Control of the temperature and thus the density of the lifting gas in order to compensate for changes of lift due to changes of atmospheric density or superheating of the lifting gas by solar radiation upon the envelope.

The problem is of great significance when helium is used as a lifting gas. It is generally conceded by those familiar with the operation of airships that valving of lifting gas must be nearly eliminated before a gas so rare and expensive as helium can be adopted for general use. Inasmuch as the known world supply of helium is largely, found in this country, it constitutes a national monopoly for military use, and its conservation is therefore imperative.

In long flights both phases of the ballasting problem assume considerable importance, but, of the two, the ballast recovery appears to be the more vital. Although the development of both projects was for a time carried on simultaneously, it was thought advisable to postpone further work on temperature control until ballast recovery reached a point where satisfactory apparatus was available. This paper, therefore, deals only with the work on ballast-recovery apparatus.

The desirability of making up ballast during flight at a rate equivalent by weight to the fuel consumption has been realized since the beginning of airship navigation. A number of means of maintaining equilibrium have been proposed, including the absorption of water vapor from the air by hygroscopic substances, compression of the lifting gas into rigid containers, and condensation of the water vapor which forms a part of the engine exhaust gas.

The first of these proposals seems impracticable on account of the small quantity of water vapor present in the air under ordinary flying conditions (about $0.0005 \mathrm{lb} . / \mathrm{ft}^{3}$ ) and the immense exposed area which would therefore be required. The second method is eliminated by the great weight of compressing machinery and high- 
pressure gas containers. The recovery of water of combustion from engine exhaust gas by cooling and condensation, however, is feasible as a method for the solution of the problem.

When the usual gasoline fuel is used, about 1.4 pounds of water vapor is formed for each pound of fuel burned. This affords an ample margin for inefficiency in the process of cooling the gas and separating the entrained moisture, so that extreme refinements are unnecessary.

\section{PREVIOUS WORK}

The recovery of water ballast from engine-exhaust gas is the subject of a publication of the (British) Advisory Committee for Aeronautics, by Guy Barr, dated September, 1915. This report discusses the principles involved and describes the operation of experimental apparatus installed on No. 1 naval airship.

The apparatus embodied a water-cooled muffler at the engine and a single air-cooled pipe of 4-inch diameter about 400 feet long. Separation of entrained moisture at the end of this pipe was accomplished by making the cooled gas bubble through water. The engine served by this apparatus had an output of 180 to 200 horsepower.

The test quoted lasted 35 minutes and yielded water in the amount of 52.2 per cent of the weight of the fuel burned. During this period there was a marked increase of temperature, both in the exhaust gas and the cooling water, indicating a decrease in the per cent recovery with further operation. In view of the crude apparatus used, the result might well be regarded as having given promise of future success.

When the work described in this paper was initiated at the Bureau of Standards the Navy Department was testing an experimental water recovery apparatus developed by the late H: S. McDewell, engineer in charge of the Aeronautic Engine Laboratory. The Navy Department, through Mr. McDewell, was kind enough to give every possible assistance to this bureau in determining the lines which might most profitably be followed in further work.

The Navy apparatus embodied a length of about 50 feet of 5 -inch finned sheet-iron pipe for initial air cooling, from which the exhaust gas passed to a jet condenser and thence through a baffle type separator to the atmosphere. From the separator and the jet condenser the water drained through settling basins to radiators and was then pumped back through the condenser jets. The excess water, representing the recovery from the exhaust gas, was drained to buckets and weighed.

This apparatus produced under favorable conditions (cold weather) 1.2 pounds of water per pound of fuel burned. Mr. McDewell must 
be credited with having demonstrated the entire feasibility of collecting exhaust water in sufficient quantities to fully compensate for the increased lift due to fuel consumption. The apparatus used in his work was constructed with little regard for weight, and as a result was far too heavy to be used on an airship. Mr. McDewell estimated that, by exercising the greatest care in design, the weight of such an apparatus could be reduced to about 6 pounds per brake horsepower.

\section{SUMMARY OF WORK AT THE BUREAU OF STANDARDS}

It is to be noted that both the systems already outlined involve the use of both water and direct air cooling. The same general scheme was at first followed by the Bureau of Standards in laying out a proposed experimental design.

This first design differed only in detail from the Navy apparatus already described. The settling basins were replaced by a centrifugal separator, and the whole apparatus was made as compact as possible. Computations based on this arrangement indicated that the apparatus, exclusive of radiators and cooling water, could be built within weight limits of about 2.0 pounds per brake horsepower.

While collecting preliminary data necessary to design such an apparatus within acceptable weight limits, a critical analysis was made of the fundamentals entering this heat transfer problem. The primary requirement to be met was that all the heat abstracted from the engine exhaust must be delivered fairly promptly to the air through which the ship moves. No large heat reservoirs could be used, nor did the cooling problem offer any similarity to that of a marine or stationary gas engine, where an unlimited quantity of cold water is available. The cycle is parallel to the cooling of a motor car or aviation engine, where, if water is used to take heat from the engine, it must, in turn, give up all this heat to the air and return to its original temperature before again abstracting heat from the engine. In such cases a water system, as opposed to direct transfer of heat from the hot body to the air, is introduced solely for the purpose of utilizing much more effectively some factors concerned in the heat-transfer process. Unless there is such a compensating feature no justification for the extra weight and inconvenience of the water system exists.

The present problem seems to differ from that of an engine cylinder, in that there seems to be no reason why, in the direct transfer of heat from the hot gas to the air, every unit of cooling surface and every degree of temperature head can not be used to maximum advantage. Accordingly, the information regarding aircraft radia- 
tors, obtained in several years of work upon this subject at the Bureau of Standards, was brought to bear upon the question of securing the most effective direct heat exchanger to take heat from a hot gas and deliver it to a stream of air.

By the time the proposed design and weight estimate for a watercooling system were available the investigation of the direct aircooling method was well under way and seemed to give promise of somewhat lower weights. The jet condenser system was held up pending the completion of the preliminary air-cooled design and was then definitely abandoned in favor of the latter, which showed a designed weight of about 1.5 pounds per brake horsepower, complete, in addition to avoiding the mechanical complications of water cooling and handling apparatus.

While the detailed design of the test apparatus was being carried forward, it was thought advisable to check the theory involved by a laboratory test of a small section similiar to the proposed full-size apparatus. With this end in view a wind tunnel of 9 inches square section was constructed, served by a centrifugal blower fan driven by a small automobile engine which also furnished the exhaust gas. A condenser was made up of standard 1-inch iron pipe, with three 20 -foot banks of three pipes in parallel, having return bends connecting the successive banks. This was installed in the tunnel and connected at one end to the engine exhaust manifold and at the other to a small baffle type separator.

Measurements were made of gasoline consumption, exhaust water collected, air velocity and temperature, and final exhaust temperature. As the results were found to closely check those expected from theoretical considerations, the work of construction of the full-size units was begun without further delay.

In general, the method is to pass the exhaust gas at high velocity through parallel lengths of about 60 feet of 1-inch aluminum tube, the outer surface of which is swept by air at a rate determined by the flying speed of the ship. For convenience the 60 feet is arranged in three banks connected by return headers, so that the over-all length is about 21 feet. To handle the quantity of exhaust gas produced by the two 150-horsepower engines to be used, with due consideration for the desired velocities and back pressures, there are 50 such cooling tubes in parallel. The whole unit presents the appearance of 150 parallel 1-inch tubes in one bank whose overall length is 21 feet. Both Models I and II have this general form, although they differ considerably in details of construction and arrangement of the hot and cold banks of tubes.

Both of these units are intended for suspension between the envelope and car on classes $\mathrm{C}$ and $\mathrm{D}$ airships of the original design and are normally slanted about $6^{\circ}$ downward to the rear to assist in 
draining the tubes of condensed water as well as to provide some cross flow of the air between them, thus avoiding the loss of efficiency due to heated air coming from a hot tube and striking a cooler tube farther along. In each case a baffle type separator is provided to collect the entrained moisture from the gaseous products leaving the condenser.

\section{GROUND TESTS}

The first of these condensers, Model I, was set up for a ground test early in November, 1921, using a stock 400-horsepower Liberty engine to provide both the exhaust gas and air stream. The propeller used, which was furnished by the engineering division, Air Service, had shown on calibration that it would absorb 307 horsepower at 1,600 revolutions per minute.

The complete set-up is shown in Figure 1, from which it will be seen that the suspension of the condensing unit is taken care of by six diagonal cables from the supporting posts, simulating as closely as possible the proposed installation on an airship. It may be mentioned here that the apparatus shown, without suspensions, separator, or exhaust-conducting pipe, weighed just 400 pounds. When installed on a ship, the total loss of lift would probably not exceed 450 pounds. As the results of this test showed the performance of the apparatus to be satisfactory, it was decided to run an endurance test of 100 hours to ascertain the effects of continued vibration and possible carbon deposition. While no provision was made to secure a uniform air blast over the condenser, thus permitting of securing sufficient physical data to check the theory of its design, it nevertheless seemed advisable to make such measurements of temperature as could be easily secured. Accordingly, another set-up was made, in which were incorporated a number of thermocouples at various points in the exhaust gas stream, as well as the necessary weighing apparatus for gasoline and collected water.

The endurance run was begun on March 11, 1922, and was terminated at the end of 90 hours April 3 because of failure of the engine. It was thought that the endurance of the condenser had been sufficiently demonstrated. The results are indicated in a later section of this paper.

After the completion of the endurance test the apparatus was taken down and packed for shipment to Langley Field. Another Liberty engine was set up and the Model II condenser swung in place for an endurance test of 50 hours. It was thought that the shorter test would be enough to show up any distinct weakness of construction and would allow of a considerable saving of money and time as well as avoiding many of the delays incident to engine trouble. 


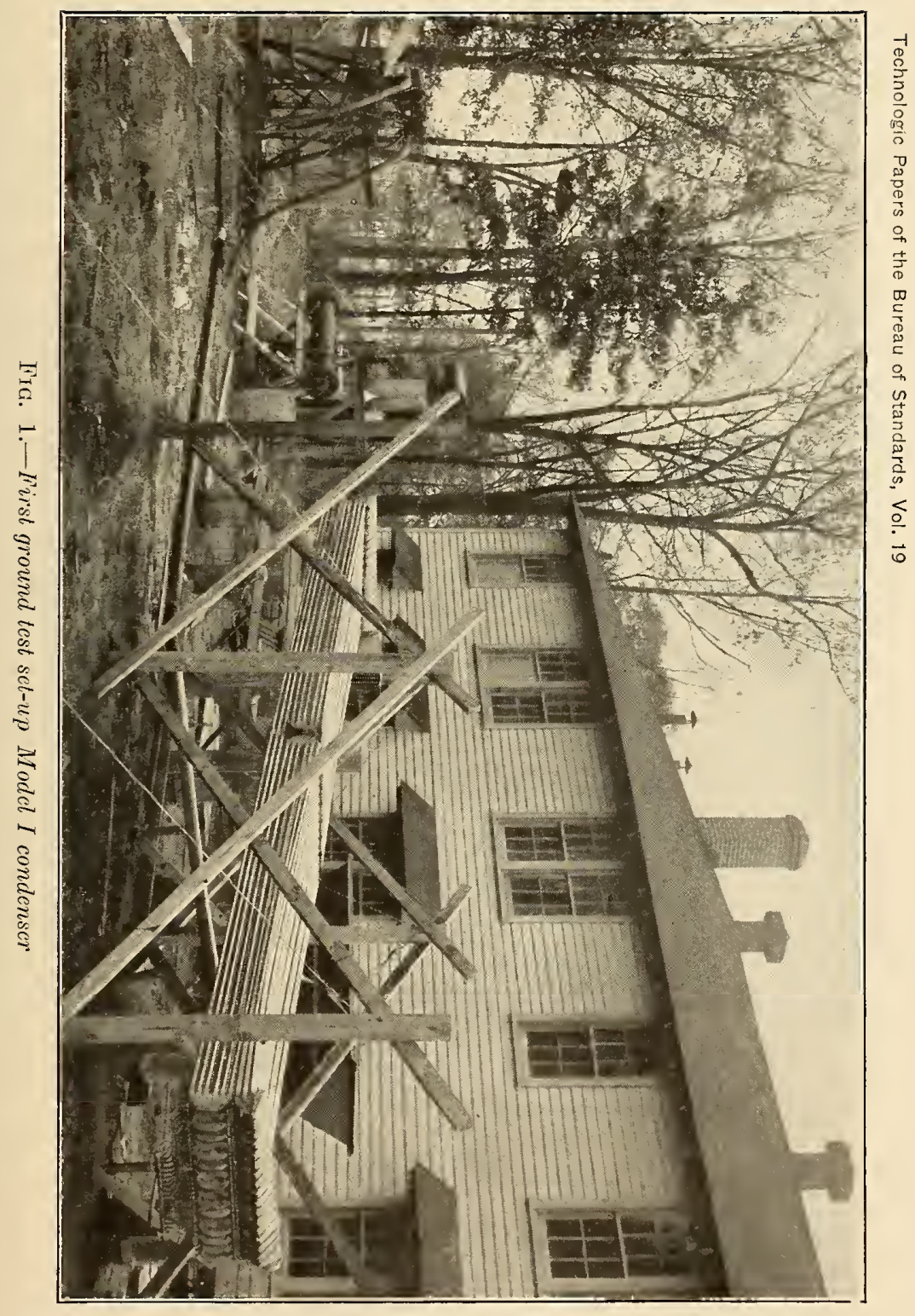




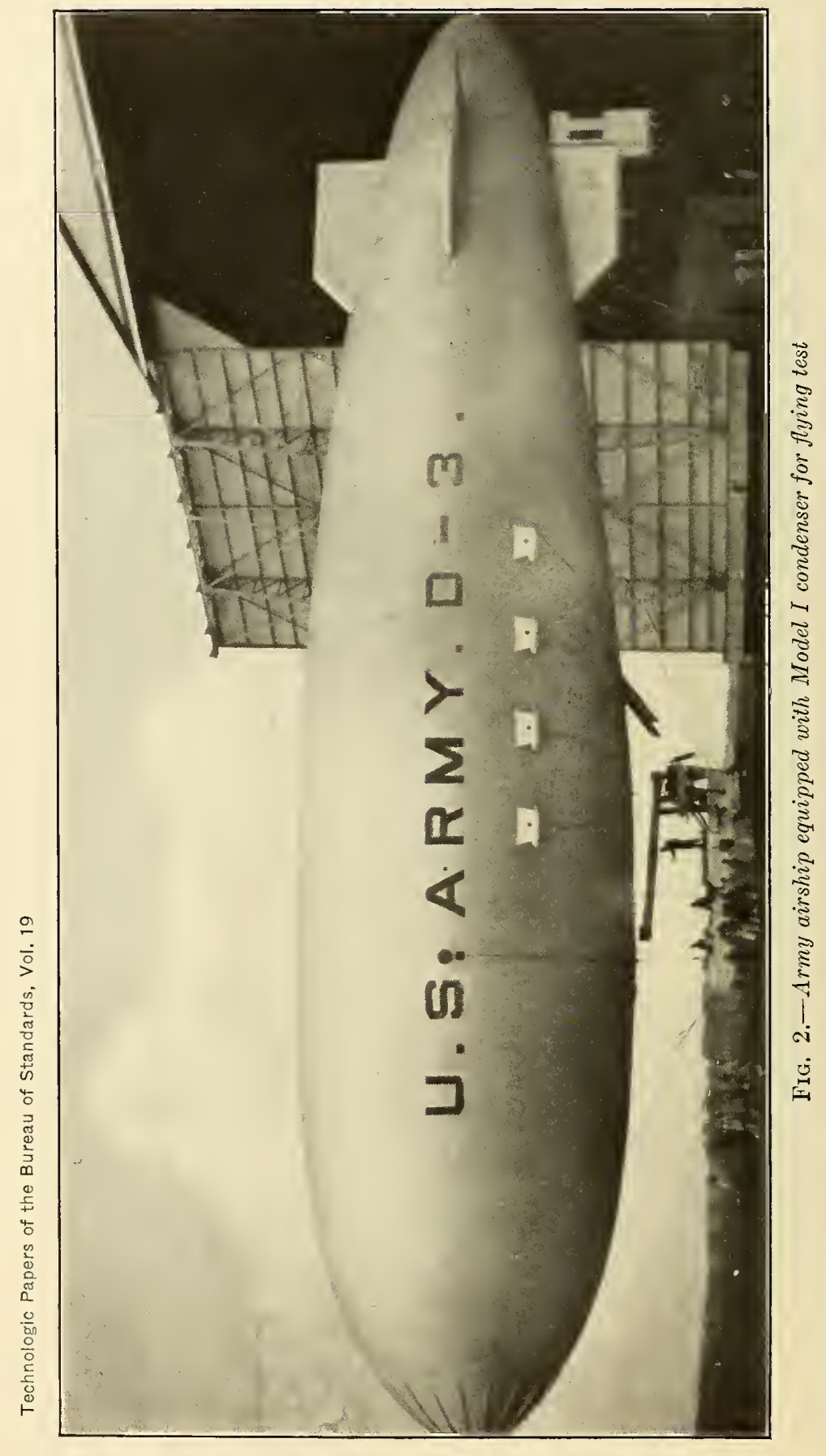


Technologic Papers of the Bureau of Standards, Vol. 19

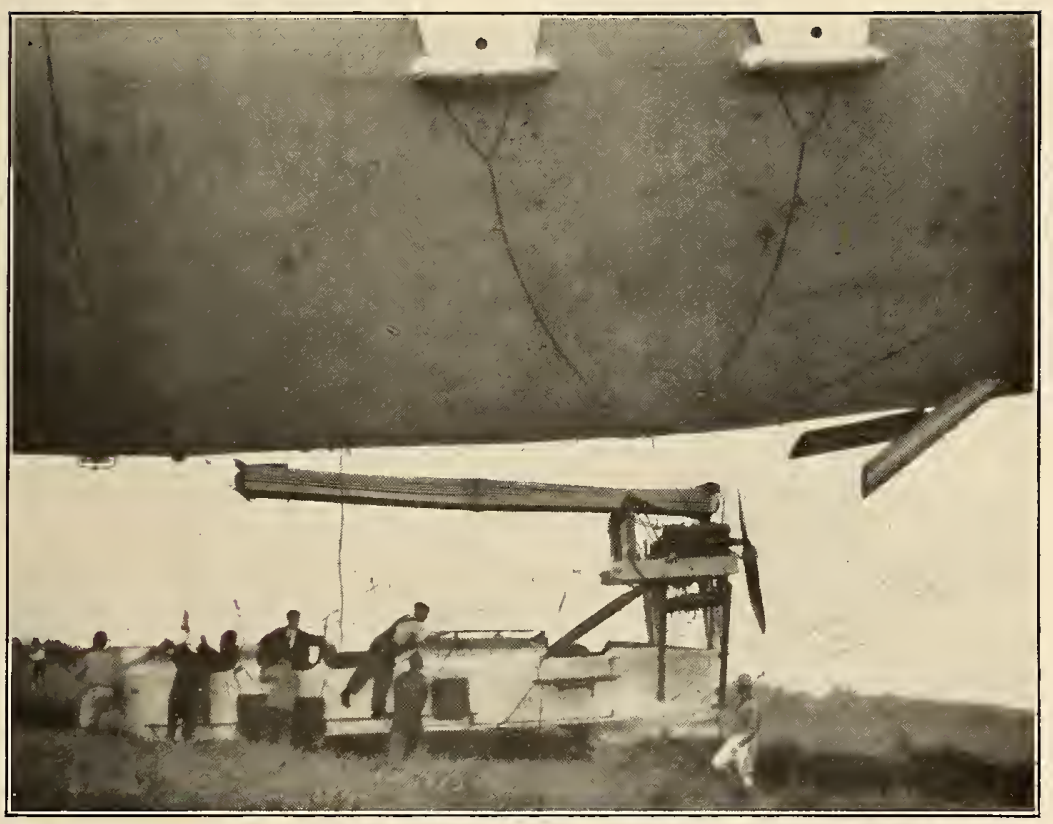

FIG. 3.-Close-up of condenser installation 


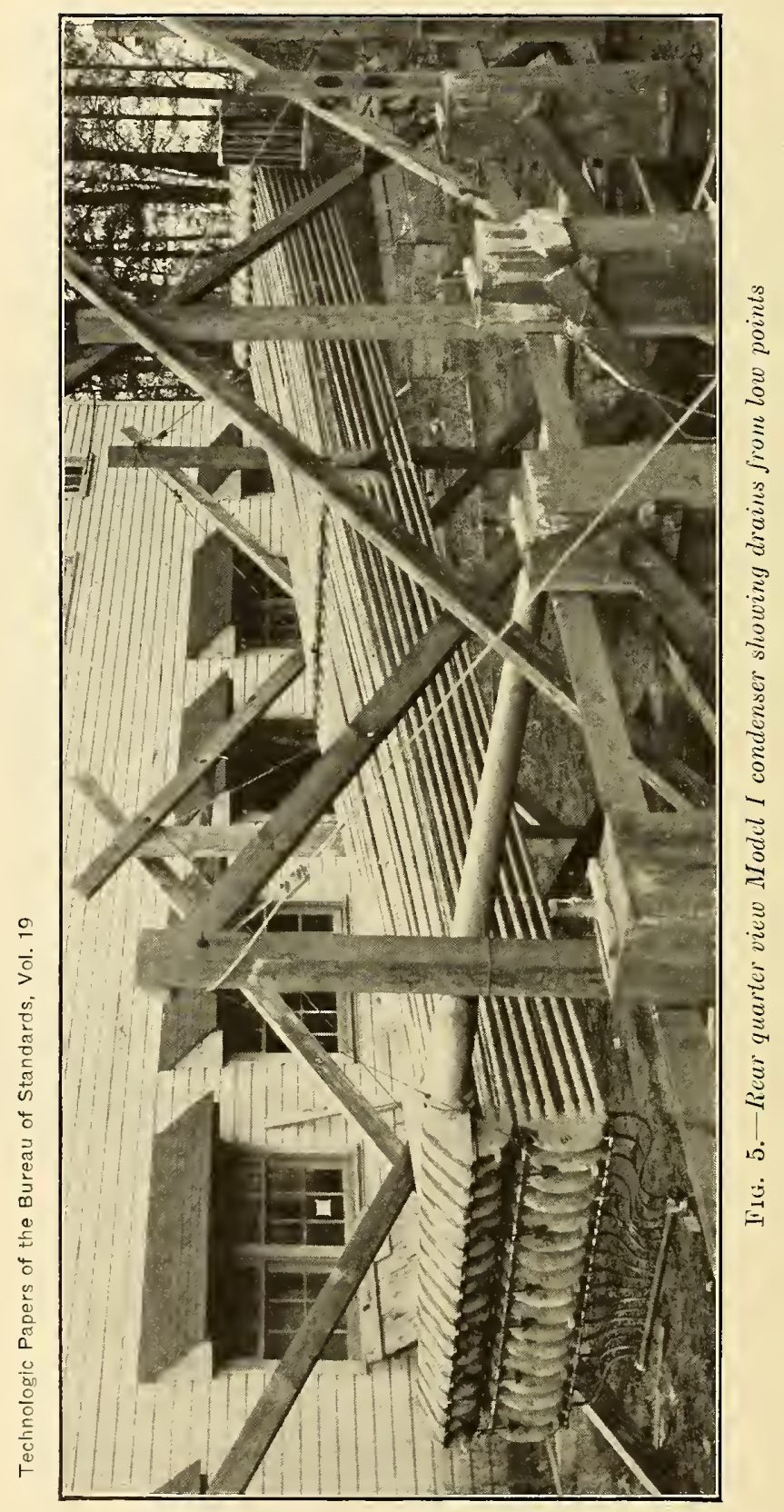




\section{FLYING TEST}

The Model I condenser was shipped to Langley Field early in the spring (1922), and authorization was secured for the use of airship $D-3$ for two months in order to carry on flight tests. The work of installation was begun about July 21, and the first flight was made on the morning of August 17.

The condenser is shown in position on the airship in Figures 2 and 3 which were taken just prior to the initial flight. A comparison of size with the whole ship, car, engines, etc., may be had in Figure 2. Figure 3 shows some of the detail looking from the left side. The separator is mounted at the upper left in Figure 3 on the side opposite the observer.

During the first flight the exhaust piping developed faults, and water leaks were discovered at the first drains from the condenser. These were repaired the next day, and the ship was again flown on the afternoon of August 18. - No further mechanical trouble appeared and, after one short flight on the morning of August 19, the ship was flown to Aberdeen Proving Grounds, where further flight work was conducted.

The $D-3$, equipped with the Model 1 condenser, was flown for a total of 53 hours, and during the greater portion of that time the apparatus was found to function satisfactorily. A detailed account of the results appears in another section of this paper.

\section{DESCRIPTION OF CONDENSERS}

In Model I condenser the tubes are arranged so that two-thirds of the total cooling area is in counterflow; that is, having the direction of flow of the exhaust gas opposite to the flow of the air stream. In addition, if the unit be considered as two halves, front and rear, the forward half is the cooler one, thus providing a secondary over-all counterflow effect. The schematic diagram (fig. 4) illustrates the flow.

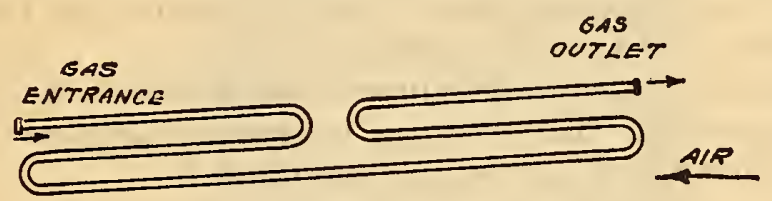

FIg. 4.-Gas and air flow, Model I

The detailed arrangement of tubes and return headers is shown in Figure 5, in which the exhaust enters at the upper left, while the air flow is from right to left.

The materials used are seamless drawn aluminum tubes with a wall thickness of 0.016 inch and headers and manifolds cast from $48599^{\circ}-25 \dagger-2$ 
" $\mathrm{F}$ " Lynite, which is an aluminum alloy containing about 10 per cent copper.

It will be noted from the photograph of component parts (fig. 9) that an attempt was made to streamline both the headers and header manifold in order to secure the best possible conditions of air flow around the castings and between the tubes, as well as to keep down the head resistance of the apparatus as a whole. The result is shown in the end view (fig. 8) looking in the direction of the air stream.

The Model II condenser (fig. 9) differs from the Model I chiefly in respect to arrangement of tubing and type of header. The flow of exhaust gas and air is two-thirds counterflow, as in the case of Model I, but no attempt was made to secure a corresponding overall counterflow effect. The schematic diagram (fig. 6) indicates the direction of gas and air flow.

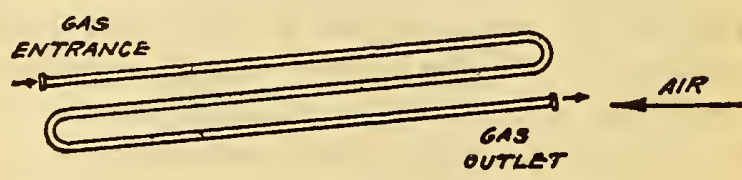

Frg. 6.-Gas and air flow, Model II

The construction is somewhat similar to that of Model I, although the headers are of an entirely different type. The same materials are employed, with the exception of the first 10-foot section, which in this case is of Benedict nickel, a commercial alloy containing 16 to 18 per cent nickel, balance copper. This material is used to avoid warping of the tubes due to the high temperatures in this section.

In Figure 9 it will be observed that in the middle layer of the upper bank many of the tubes have taken a decided permanent set. This is due to the poor gas distribution between the three layers of the bank in question. The exhaust gas tends to flow through the central layer on account of the more direct path as opposed to the elbow nipples of the outer tubes. For this reason the center tubes are hotter and their expansion greater, with the result that they fail as long columns. These tubes are of aluminum.

It is noted that some of the upper tubes at the far end (Benedict nickel) are also bent. This, however, is a result of accidental mechanical stresses and not of any temperature effect.

The number of parallel tubes per bank in this condenser is 50, and each bank is composed of two 10-foot lengths, end to end, so that a total of 3,000 feet of tubing is used. For better mechanical stiffness and strength the aluminum tubing used has a wall thickness of 0.022 inch instead of 0.016 inch. This is the thinnest walled tube made as a stock product by manufacturers of aluminum and is far cheaper 


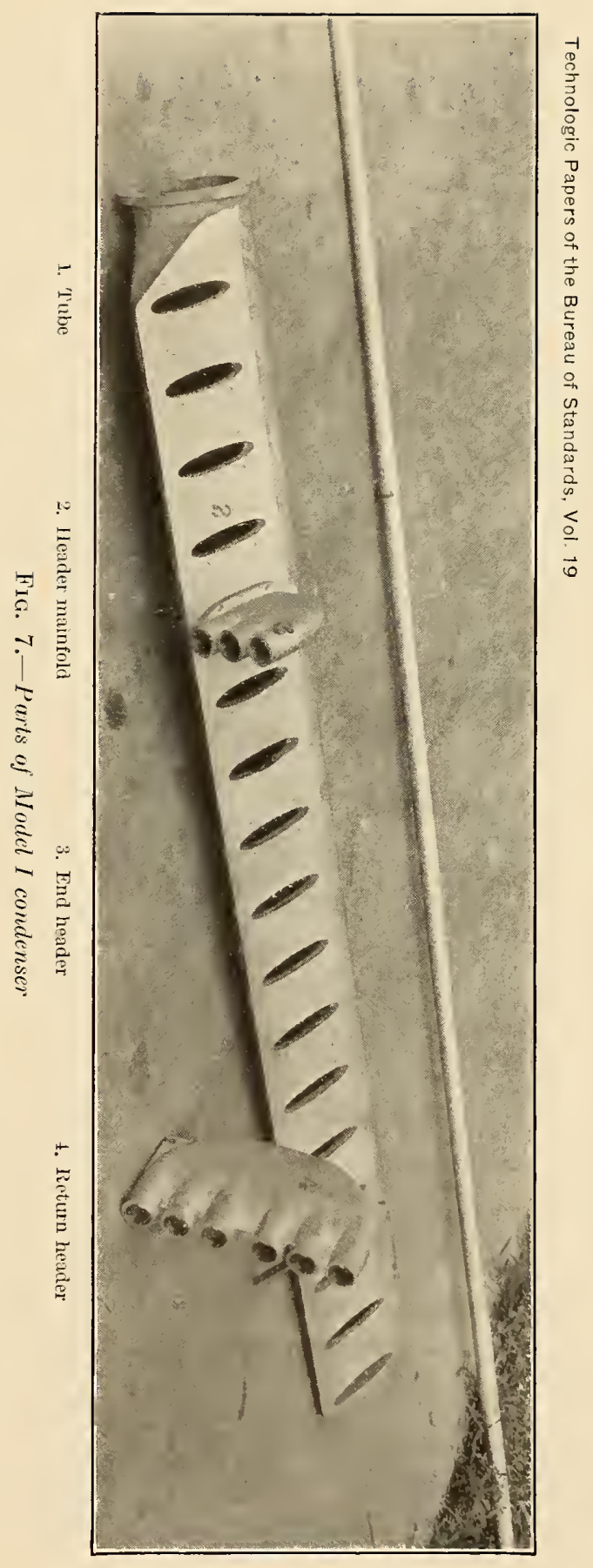




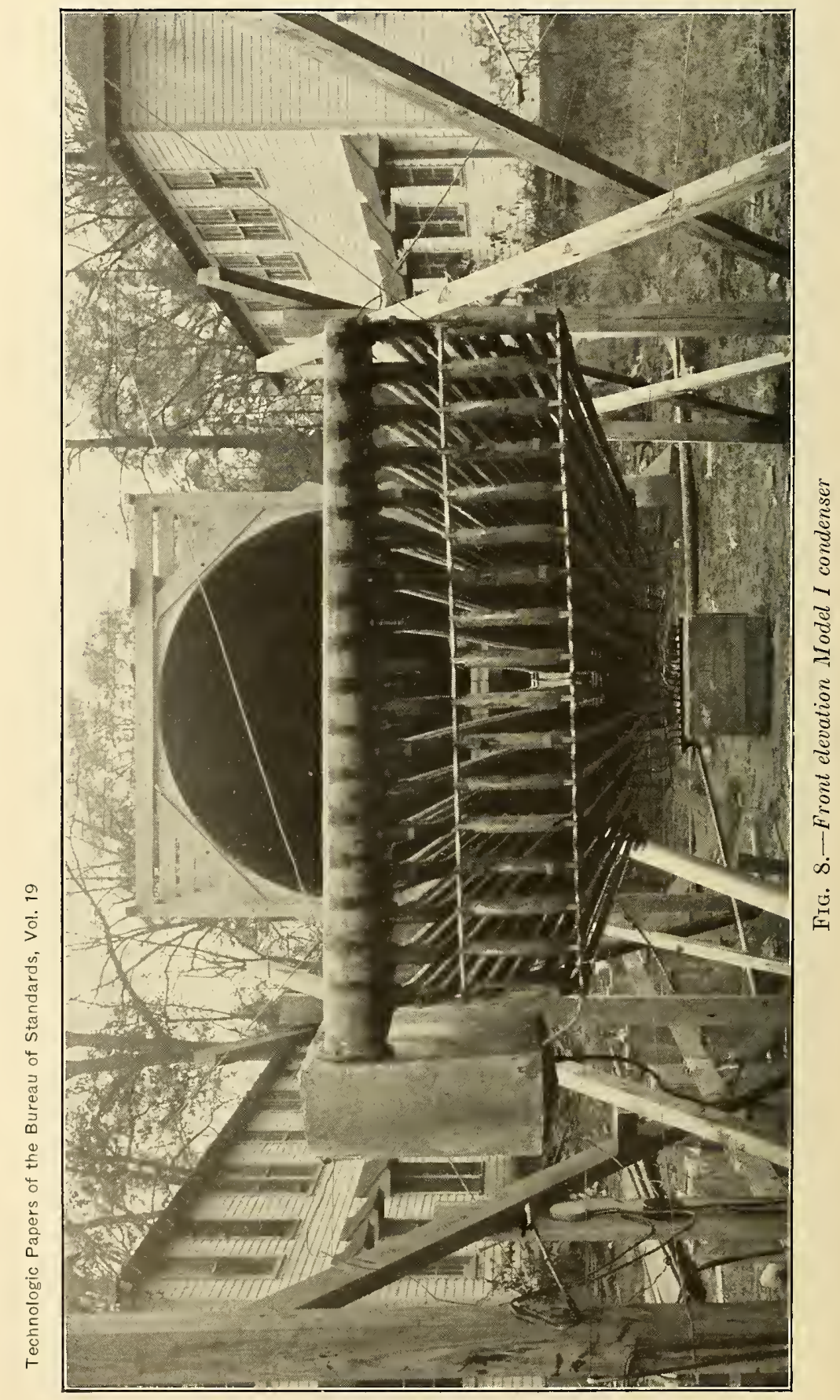


Technologic Papers of the Bureau of Standards, Vol. 19

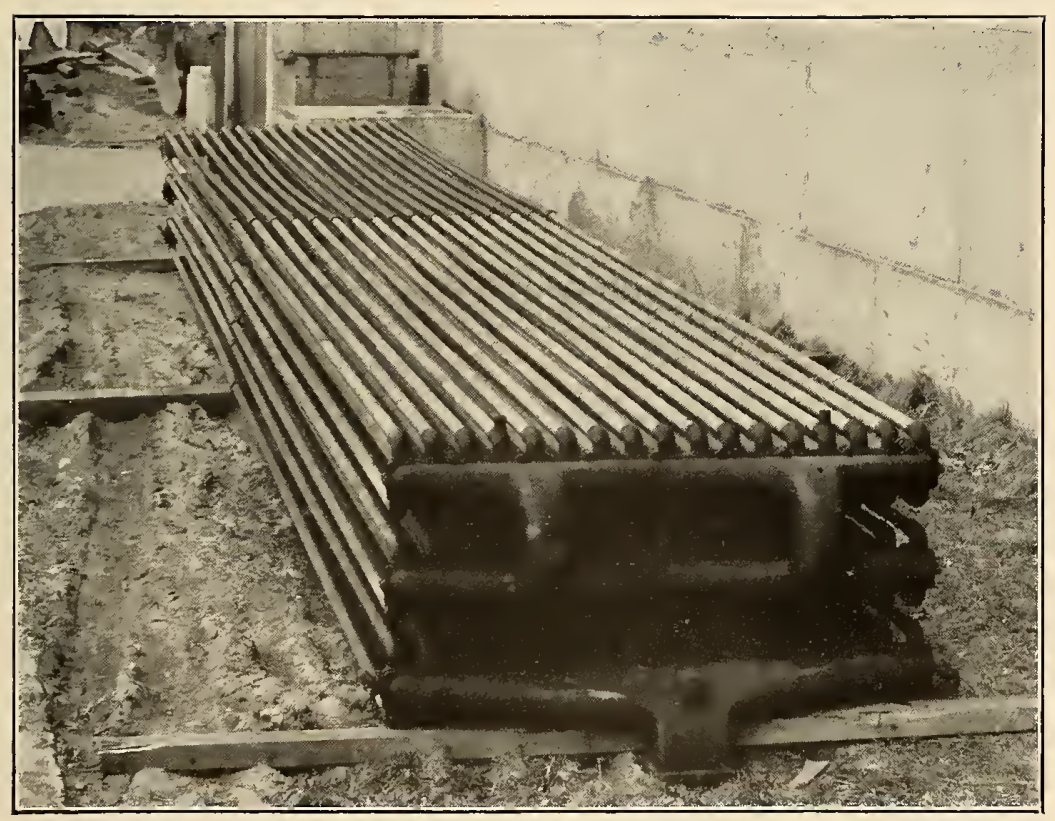

FIG. 9.-Front quarter view Model II condenser 

than the thinner material used in Model I. The Benedict nickel, ${ }^{2}$ which is very easily worked, was drawn to a thickness of 0.010 to 0.012 inch, making it about 40 per cent heavier than the 0.022 -inch aluminum tube. The actual weights per foot are as follows:

0.010 to 0.012 inch Benedict nickel

0.022-inch aluminum.

This makes the total weight of tubing 274.6 pounds, which is about 50 per cent higher than that of Model $I$. The increase in tube weight, however, is offset by a decrease in the casting weight, to such an extent that the Model II condenser is only about 9 per cent heavier than Model I. The actual weights without suspensions, exhaust-pipe connections, or separators are as follows:

Model I. Pounds

Model II....

It is probable that with exhaust-pipe connections of ample flexibility, freely moving slip joints to take up linear expansion, and a header design providing good gas distribution the added weight of Benedict nickel tubing would not be justifiable.

\section{SEPARATORS}

The importance of the separators for the collection of entrained moisture can not be overemphasized. No matter how low a temperature is reached in cooling the exhaust gases, much of the water condensed remains in the form of spray and is carried along by the gases until the separator is reached. In the absence of such a device this represents a loss of about 50 per cent of the water condensed.

Since the functioning of the separators is the same for both condensers, only the Model II will be described in detail. This separator was bolted up directly to the exit elbow (shown in fig. 9) and extended back under the condenser, where its free end was supported by wires extending diagonally upward between the tubes to the header casting above.

The separator is shown in some detail in Figures 10 and 11. Its action depends upon the drops of water being thrown against the baffles shown in Figure 10 and guided by the small vertical gutters to holes punched through the bottom to a false bottom, from which the collected water is drained to the ballast tanks.

The exhaust gas enters at the upper right (fig. 11), passes between the baffles, and escapes at the left. It will be observed that there is a lip on the outlet end to prevent the separated water washing along the bottom past the holes and so escaping with the gas.

The separator is built of tinned sheet iron and is soldered together. This material was selected purely because of its availability and the

2 Benedict nickel is a copper nickel alloy used largely in the manufacture of plumbing txxtures on account of its noncorrosive character. It is easily worked and has a bigher tensile strength than aluminum. 
ease with which it can be worked. Some noncorrosive material, such as aluminum or a copper-nickel alloy, might be a decided improvement.

The Model I separator, differing only in outer shape, may be seen at the upper right, Figure 5, and upper left, Figure 8.

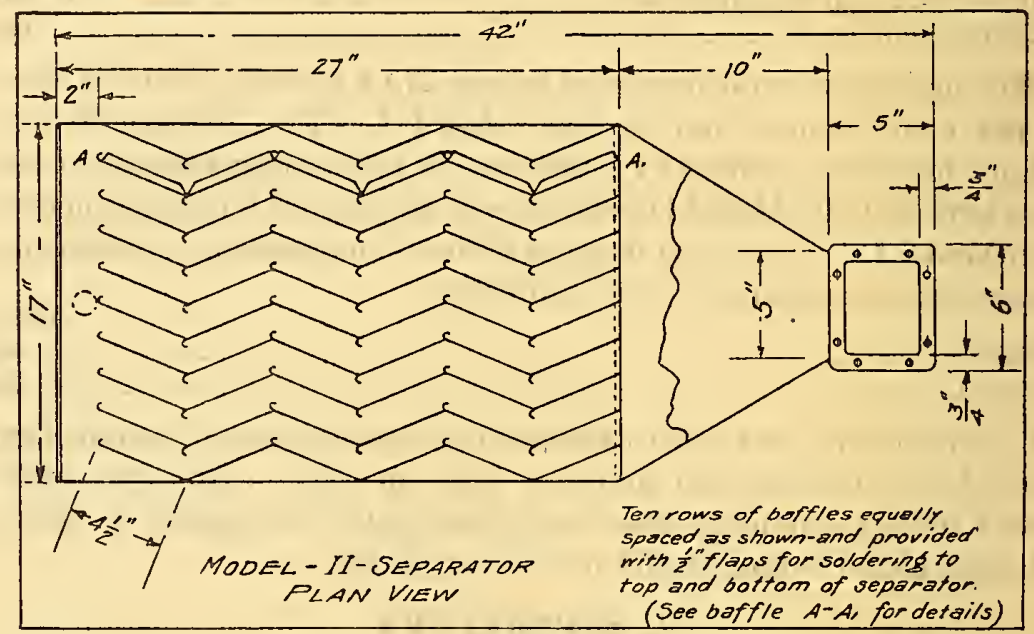

FIG. 10

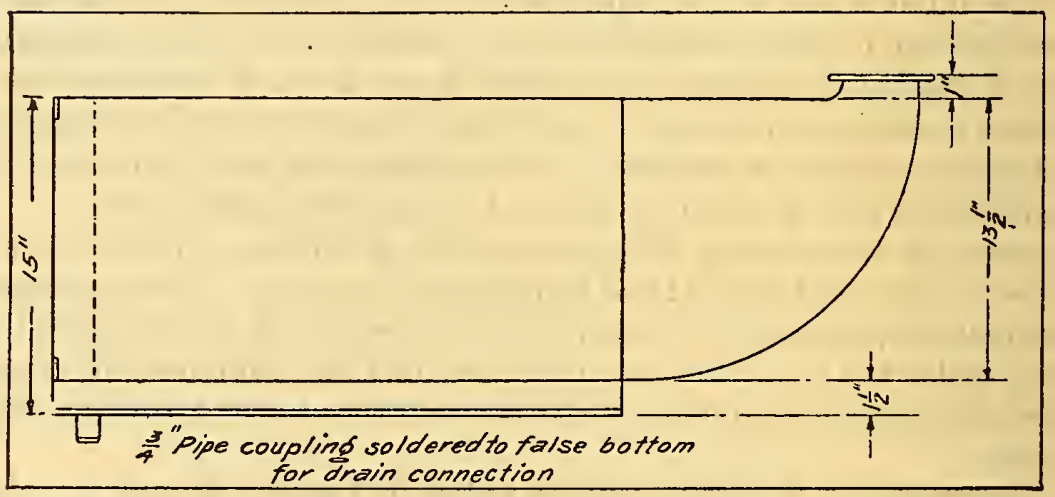

FIG. 11.-Model II separator, elevation

\section{GROUND TEST RESULTS, MODEL I}

The results of the 90-hour ground test of the Model I condenser are shown graphically on Figure 12. A summary of the results follows:

Average air speed entering condenser-_._._._._. miles per hour._ 48

Average air temperature...............

Total weight of fuel used _.

Total weight of water collected . .

Water collected, ${ }^{3}$-._._._._.

3 The water recoverable, water condensed, and water collected, when expressed as per cent, are based upon the weight of the gasoline or other fuel hurned. Thus, a recovery or collection of 100 per cent exactly compensates for the wcight of fuel hurned. 
The recovery is somewhat low, but this is not inherently a fault of the condenser. Trouble was experienced during the test with misfiring of the engine, cracked exhaust ducts, small water leaks at drain connections and thermocouplc bushings, and clogged drainpipes. Improvements in construction should obviate these difficulties and materially increase the recovery.

In conducting this test it was intended that a "helium heatcr," for regulating the temperature of the lifting gas should bc tested at the same time. This apparatus was connected into the exhaust line by a by-pass valve which allowed of passing the exhaust gas at will through the heater or direct to the condenser. The valve platc was of brass, clamped to a steel operating stem by set screws.

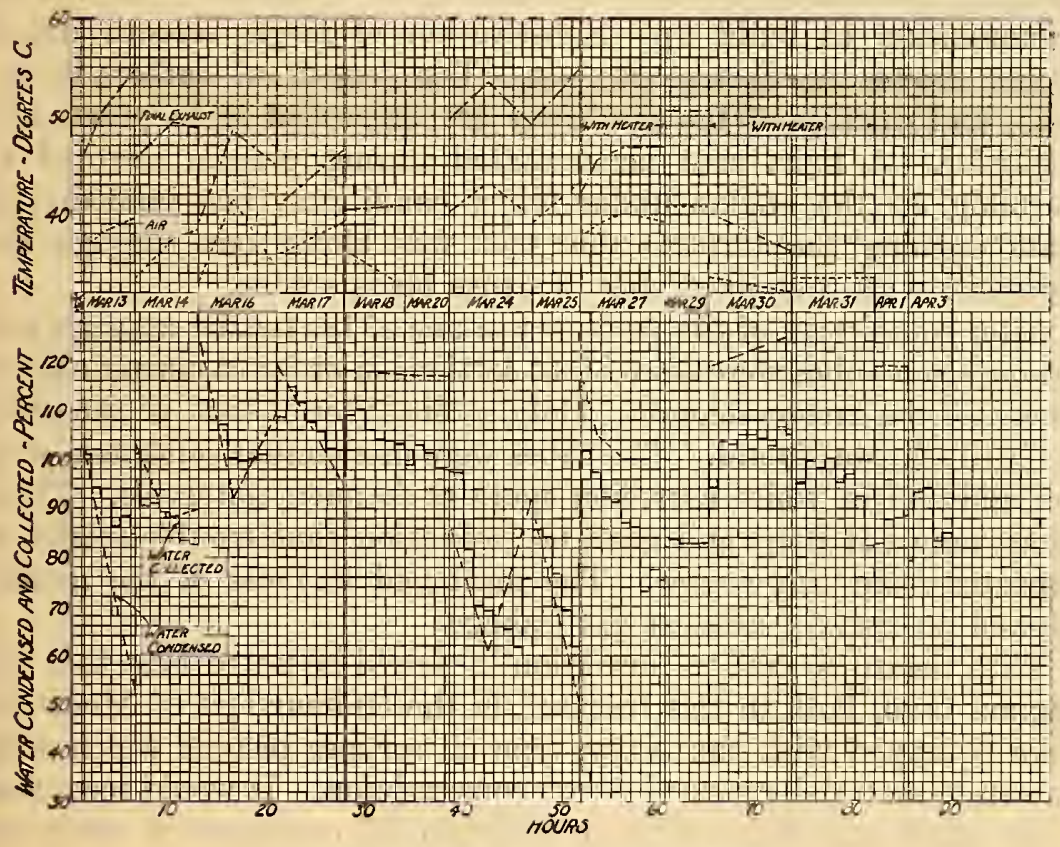

90 HOWR ENOURANCE RUN MOCLLI CONOENSER

FIG. 12

Shortly after completion of 50 hours of operation the sct screws loosened, dropping the valve to the position necessary to cut in the heater. As the valve was very inaccessible, and inasmuch as the test was for the purpose of demonstrating the mechanical strength of the condenser unit, the run was continucd under the new conditions.

The point at which the helium heater was cut in is readily observed on Figure 12, from which it will be secn that the change came during the fifty-second hour of operation. For this reason the recovery 
and fuel consumption have also been computed separately for the first 50 hours of the run. The results follow:

Average air temperature $\circ \mathrm{C}_{--}$16. 5

Total gasoline burned........

Total water collected._._.

Water collected._._. 94.4

These results indicate that the decrease of the exhaust gas temperature at the entrance to the condenser was more than offset by the increase in the losses already mentioned during the last 40 hours of the run.

The carbon, or soot, in the water collected took the form of a light foamy scum or a mushy sludge. The latter gave some trouble by clogging drain tubes wherever a contraction or shoulder allowed an accumulation to build up. Substitution of large, smooth drains should prove an effective remedy. The deposit of carbon in the tubes and castings of the condenser proper proved to be practically negligible. A light soot accumulated during periods devoted to warming up the engine under idling conditions, but immediately upon opening the throttle this soot was blown out through the separator with the appearance of dense black smoke.

After completion of the 90-hour run one of the header castings and the adjacent tubes were sawed into sections in order to permit examination of the carbon deposit. Only a thin layer of soot, of the order of 0.01 inch, was found. The tubes were in a similar condition, with the addition of white corrosion spots at frequent intervals. These spots were not deep and gave no indication that trouble might be expected from this source. The machined surfaces of the nipples showed no signs of exhaust gas leakage.

With regard to carbon formation it should be noted here that the engines used, both in this test and in the 50-hour test of Model II, were equipped with the Navy type oil scraper pistons which were known to materially reduce the oil consumption. It would seem that every effort should be made to minimize oil consumption when exhaust water recovery apparatus is to be employed.

Some of the castings used in the construction of the Model I condenser had been found porous and were plugged with aluminum solder in order to stand the leakage test. This solder melted and oozed from the pores of the exhaust extrance header manifold during the preliminary ground test, but the leakage of gas was thought to be so small as not to warrant replacement. In the light of this experience, however, it would be well to specify that castings for this purpose be required to stand a leakage test without repair of any kind.

No mechanical failure of any kind occurred in the Model I unit during all test work to which it was subjected, and the structural 
design is therefore concluded to be sound, although it is realized that many modifications may prove desirable in laying out apparatus for service use.

\section{GROUND TEST RESULTS, MODEL II}

Ground test of the Model II condenser is charted in Figure 13. Summarized results follow:

Average air speed entering condenser. 35

Average air temperature._. 20

Total weight fuel used___._.

Total weight water collected

Water collected._. 65.0

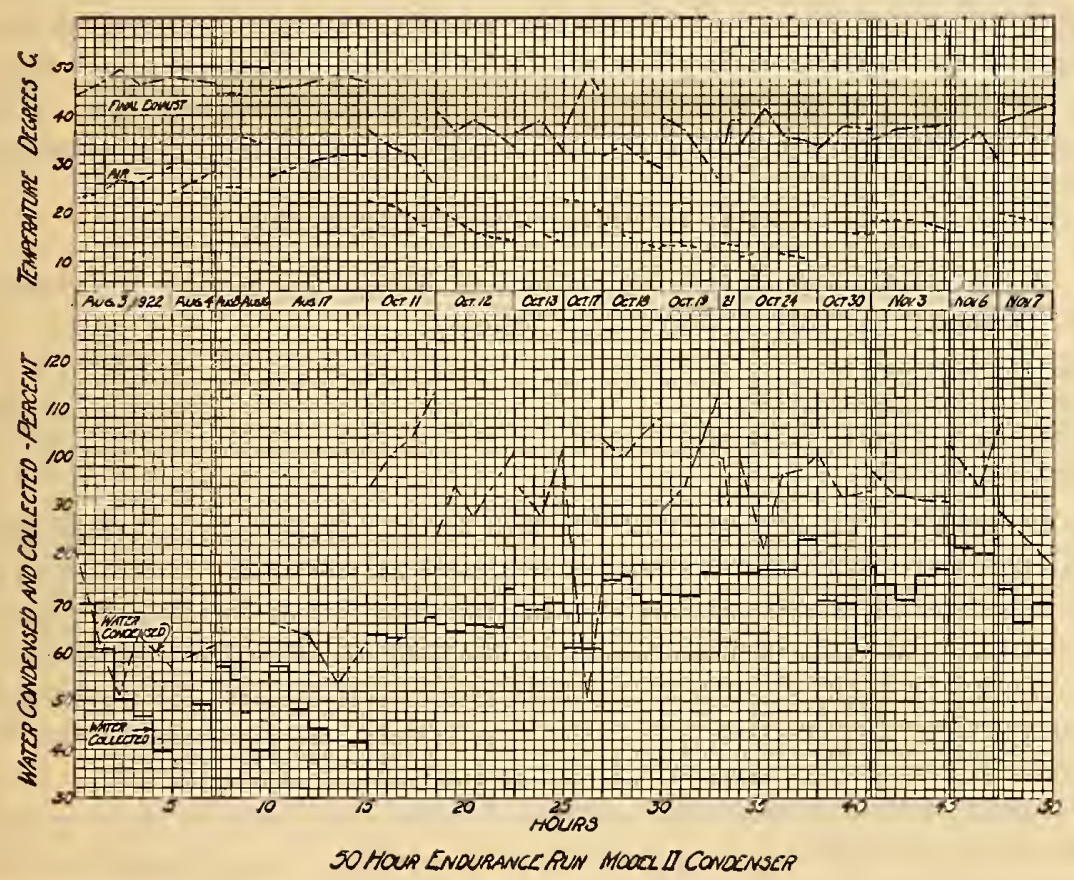

FIG. 13

The postponement of this test for several months resulted in serious rusting of the flexible leads from the exhaust manifolds of the engine to the exhaust pipe line to the condenser, and, as a consequence, the resumption of test work was marked by persistent occurrence of breaks in the flexible piping with attendant leakage of exhaust gas. Trouble was also encountered with clogging of the drain from the separator, owing to rust and sediment deposits which would not be expected during continuous or semicontinuous operation.

In Figure 13 the line of water condensed is obtained by referring points from the line of final exhaust temperature to Figure 18, assuming the mixture ratio to have been $15: 1$. It will be noted 
that the line of water condensed is at least in the same general range as that of water collected during the few runs made in August, whereas with the runs of October these lines at once diverge, so that there is an average difference of perhaps 20 per cent. This is believed to result from exhaust gas leaks and waste of water due to persistent stoppage of the separator drain. This stoppage causes the false bottom of the separator to fill and overflow, so that the water separated by the baffles from the issuing exhaust gas can not drain off and is swept out by the gas.

The only mechanical failure was occasioned by differential expansion of the entrance header elbow and the header bolted to it. The entrance elbow casting was, of course, hotter than the header proper, and the upper flange of the elbow warped upward, pulling off the lugs of the corresponding flange of the header. This occurred early in the test and was remedied by passing a bolt through the elbow casting, thus drawing down the upper edge and holding it permanently in place.

\section{FLYING TEST RESULTS}

A condensed log of the flight tests of Model I condenser is shown in Table 1. Totals and averages follow:

Air temperature . . . .

Total weight fuel burned._................................ 2, 799

Total weight water collected_._._._.

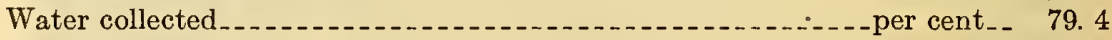

In making up the separator drain from whatever materials and fittings were available a shoulder was left at the point of connection of the drainpipe and separator, and this resulted in the loss of a considerable quantity of water, due to clogging of the drain by carbon.

Owing to lack of data as regards engine power and final exhaust temperature and to the variations in air speed, no comparison can be made between the theoretical and actual results on this test. It is thought, however, that the leakage of exhaust water due to stoppage of the separator drain and sticking of the ballast-dumping valve may easily account for the difference in weight between the water collected and fuel burned.

It is to be noted that condensers designed for an air temperature of $15^{\circ} \mathrm{C}$. can not be expected to condense sufficient water to completely compensate for the weight of fuel burned when higher temperatures are encountered, as in summer flying. Figure 14 indicates the variation of water condensed with change of air temperature based on the design of the Model II condenser. In computing the points for this curve all other conditions are assumed as constant.

In the flight test, as in the ground test of the same apparatus, no trouble of any kind was experienced with the condenser proper. Some difficulties were encountered with accessories, such as exhaust 
piping and drain tubes, but these parts were of a makeshift nature and should give no trouble in a service unit whose parts are well designed and constructed.

It is worthy of comment that the installation of the Model I condenser on the $D-3$ produced no appreciable decrease in the ship's

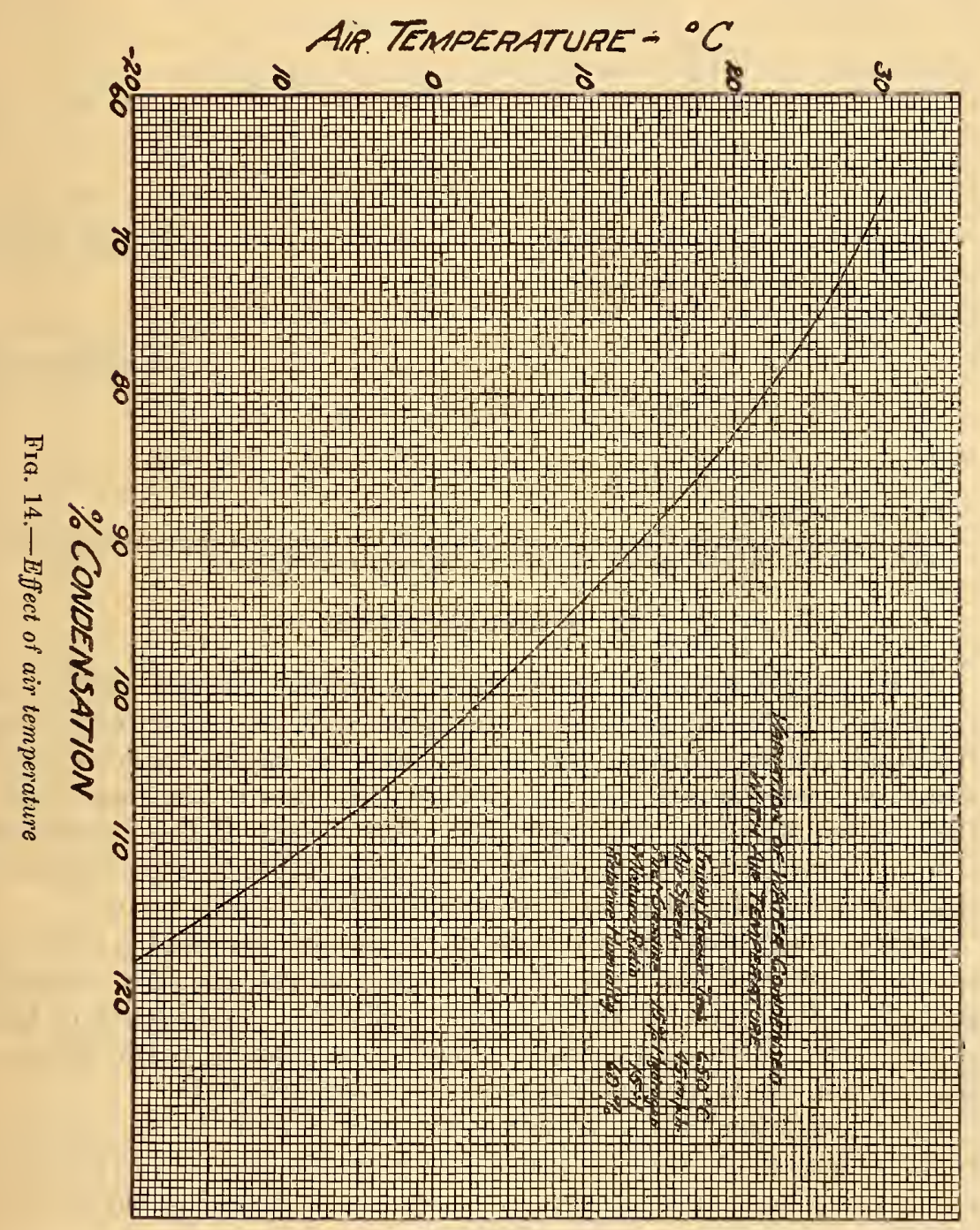

flying speed at a given propeller speed. This was contrary to expectations, but may be readily credited when the immense projected frontal arca of the ship is taken into account.

$$
48599^{\circ}-25 \dagger-3
$$


TABLE 1.-Summary of fight tests on Model I condenser

\begin{tabular}{|c|c|c|c|c|c|c|c|c|c|c|}
\hline \multirow{2}{*}{ Flight No. } & \multicolumn{2}{|c|}{ Time } & \multirow{2}{*}{$\begin{array}{l}\text { Mean } \\
\text { air } \\
\text { tem- } \\
\text { pera- } \\
\text { ture }\end{array}$} & \multirow{2}{*}{$\left|\begin{array}{c}\text { Air } \\
\text { speed }\end{array}\right|$} & \multirow{2}{*}{$\begin{array}{l}\text { Alti- } \\
\text { tude }\end{array}$} & \multirow{2}{*}{ Engine } & \multirow{2}{*}{ Water } & \multirow{2}{*}{$\begin{array}{l}\text { Gaso- } \\
\text { line }\end{array}$} & \multirow{2}{*}{$\begin{array}{c}\text { Water } \\
\text { col- } \\
\text { lected }\end{array}$} & \multirow{2}{*}{ Remarks } \\
\hline & Hours & $\begin{array}{l}\text { Min- } \\
\text { utes }\end{array}$ & & & & & & & & \\
\hline & $\begin{array}{l}3 \\
3 \\
2 \\
2\end{array}$ & $\begin{array}{l}13 \\
18 \\
52 \\
47\end{array}$ & $\begin{array}{l}\circ C . \\
20.5 \\
24.1 \\
23.5 \\
24.4\end{array}$ & $\begin{array}{c}M . \\
p . h .\end{array}$ & $\begin{array}{r}\text { Feet } \\
1,000 \\
1,000 \\
800 \\
900\end{array}$ & $\begin{array}{r}\text { R. } p . m . \\
900 \\
1,100 \\
1,000 \\
1,200\end{array}$ & $\begin{array}{l}\text { Pounds } \\
206 \\
254 \\
210 \\
212\end{array}$ & $\mid \begin{array}{c}\text { Pounds } \\
242.5 \\
331 \\
285 \\
332\end{array}$ & \begin{tabular}{|c} 
Per \\
cent \\
84.9 \\
76.7 \\
73.7 \\
163.8
\end{tabular} & Separator drain clog \\
\hline $5 \ldots$ & 3 & 9 & 20.5 & 39 & 1,000 & 1,000 & 232.5 & 266 & 87.3 & Gasoline record uncer- \\
\hline $6 \ldots$ & $\begin{array}{l}4 \\
2\end{array}$ & $\begin{array}{l}24 \\
59\end{array}$ & 22.7 & $\begin{array}{l}37 \\
46\end{array}$ & $\begin{array}{r}950 \\
1,250\end{array}$ & $\begin{array}{r}900 \\
1,100\end{array}$ & 227 & 302 & 75.2 & Water spilled in drain. \\
\hline & 3 & 18 & -... & 34 & & 900 & & & & $\begin{array}{l}\text { Wag. } \\
\text { Water leaked through } \\
\text { emergency release } \\
\text { valve. }\end{array}$ \\
\hline . & $\begin{array}{l}3 \\
3 \\
3\end{array}$ & $\begin{aligned} 11 \\
1\end{aligned}$ & $\begin{array}{l}21.5 \\
18.5\end{array}$ & $\begin{array}{l}38 \\
44\end{array}$ & $\begin{array}{l}800 \\
850\end{array}$ & $\begin{array}{r}900 \\
1,100\end{array}$ & $\begin{array}{l}180 \\
278\end{array}$ & $\begin{array}{l}260.5 \\
309.5\end{array}$ & $\begin{array}{l}69.1 \\
89.8\end{array}$ & \\
\hline $12 \ldots$ & 1 & 0 & 24.5 & 48 & 900 & 1,200 & 371 & 471 & 78.8 & $\begin{array}{l}\text { water lost. } \\
\text { Flight abandoned due } \\
\text { to oil leak on left } \\
\text { motor. }\end{array}$ \\
\hline Mean. & & & 22.3 & & & Total... & $2,170.5$ & $2,799.5$ & 79.4 & Mean. \\
\hline
\end{tabular}

1 This value not included.

Note--Six preliminary flights were made (total time 12 hours 46 minutes) in order to eliminate minor mechanical defects. The average water collected for these flights was 72.4 per cent.

\section{CONCLUSIONS}

Although no claim is made for the present general design as representing the ultimate form of ballast-recovery apparatus, the feasibility of condensation of water from the engine exhaust as a means of compensating for the increased lift due to the loss of the fuel burned has been demonstrated. The weight of the apparatus is not excessive and can be wholly compensated for by a corresponding decrease in the weight of the water ballast usually carried.

Owing to the large frontal area of an airship, the head resistance of a condenser of the type thus far used represents such a small portion of the whole as to be nearly negligible. Condensers of the general type of Models I and II, having no moving parts, require little attention and should have a satisfactory flying life.

In cold weather, with a condensation in excess of the fuel equilibrium requirements, the exhaust water may also be used to at least partly compensate for the change in lift due to changing barometric pressure or temperature of the lifting gas.

Although some assumptions used in the design work appear to be only rough approximations, none of the test results seem to indicate any great error within the range of conditions thus far encountered. 


\section{PART II-THEORY}

\section{NOMENCLATURE}

In reviewing the theory involved in the process of obtaining water from the engine exhaust gas it may be well, in order to avoid confusion, to first discuss the nomenclature used. Reference is made to Figure 15, in which vertical distances represent weights of the quantities indicated.

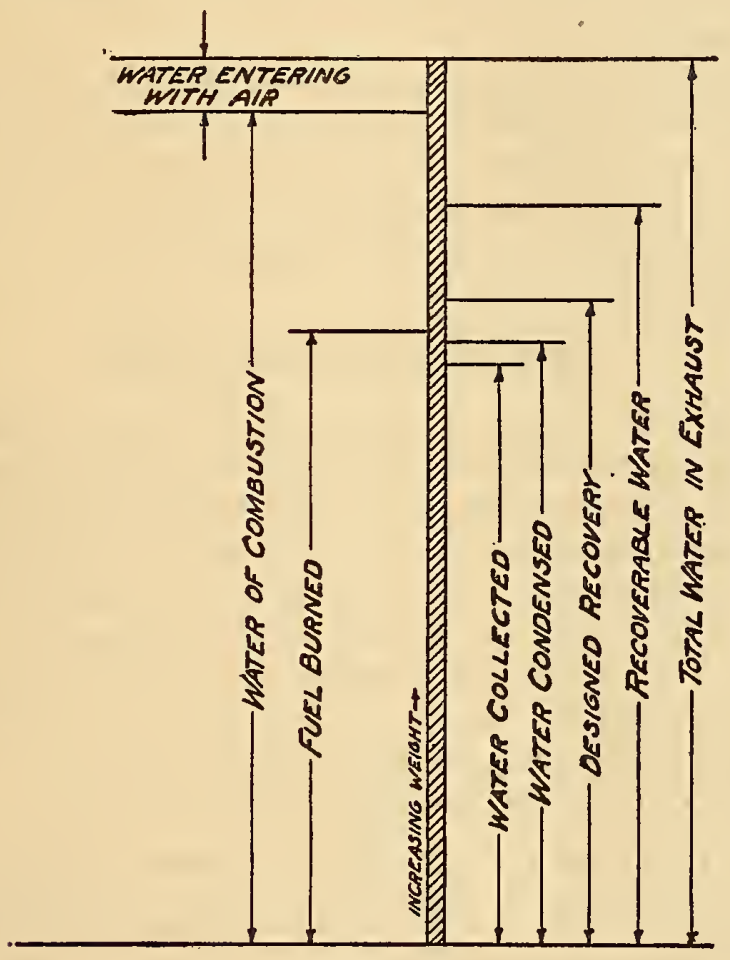

Fig. 15

The fuel burned is, of course, the basis upon which the other quantities are determined. The total water in the exhaust gas is the sum of the water of combustion and the moisture entering with the carburetor air. This quantity depends upon the kind of fuel and, to a small extent, upon the mixture ratio and humidity. When using gasoline, there is present more than 1.4 pounds of water for every pound of fuel burned.

Since the amount of water lost as vapor depends upon the exhaust gas final temperature, and since, in an air-cooled system, the limit of cooling is the air temperature itself, it at once becomes apparent that the recoverable water is the total minus the vapor necessary to saturate the gaseous exhaust products at air temperature. 
The designed recovery is, of course, limited by the recoverable water as determined by an assumed air temperature. It may be arbitrarily placed at any value less than that of the recoverable water but would not ordinarily be less than the fuel burned.

Since the designed recovery is based upon a designed final exhaust temperature, it is evident that error in design assumptions or changes in flying speed or air temperature will change this final temperature and, therefore, the water actually condensed. The water condensed may be either greater or less than the designed recovery but is represented as showing a loss.

In the collection of the water condensed leaks of any kind, as well as faulty separation of entrained moisture, will lower the quantity actually available as ballast. The water collected is therefore almost certain to be less than that actually condensed.

All of the quantities shown, when expressed as per cent, are based upon the weight of fuel burned.

\section{DESIGN CONSIDERATIONS}

The design of the condensing apparatus is dependent upon a large number of variables which may best be taken up as they appear.

It is at once apparent that the water condensed is dependent upon exhaust gas composition and its final temperature. The first of these is readily determined when the chemical composition of the fuel, ratio of air to fuel, and relative humidity and temperature of the air are known. The final exhaust temperature, however, is a function of the length, diameter, spacing and number of condenser tubes, mass flow and initial temperature of exhaust gas, and the velocity and temperature of the air flowing past the tubes.

\section{EFFECT OF FUEL COMPOSITION}

Taking first the effect of different fuels, Figure 16 shows the water condensed in per cent by weight of the fuel burned, plotted against the final exhaust temperature, for a number of liquid fuels.

In order to arrive at the curves shown it was necessary to make assumptions for carburetor air composition, temperature and humidity, and mixture ratio, or pounds air per pound fuel.

The air composition is approximately oxygen 23 per cent and nitrogen 77 per cent by weight. The air temperature was assumed to be $15^{\circ} \mathrm{C}$. lower than that of the exhaust products leaving the condenser. It is obvious that the exhaust gas will never be cooled to the temperature of the air. The relative humidity was assumed as 60 per cent, which is an approximate average for all parts of this country for the whole year for altitudes less than 5,000 feet. As a basis of comparison of the different fuels their chemically correct air-fuel ratios were used. 
The condensed water per pound of fuel is, of course, the water of combustion plus the moisture entering with the air, minus the water issuing as vapor with the cooled exhaust products. It may be well to follow through the computation with one of the fuels involved.

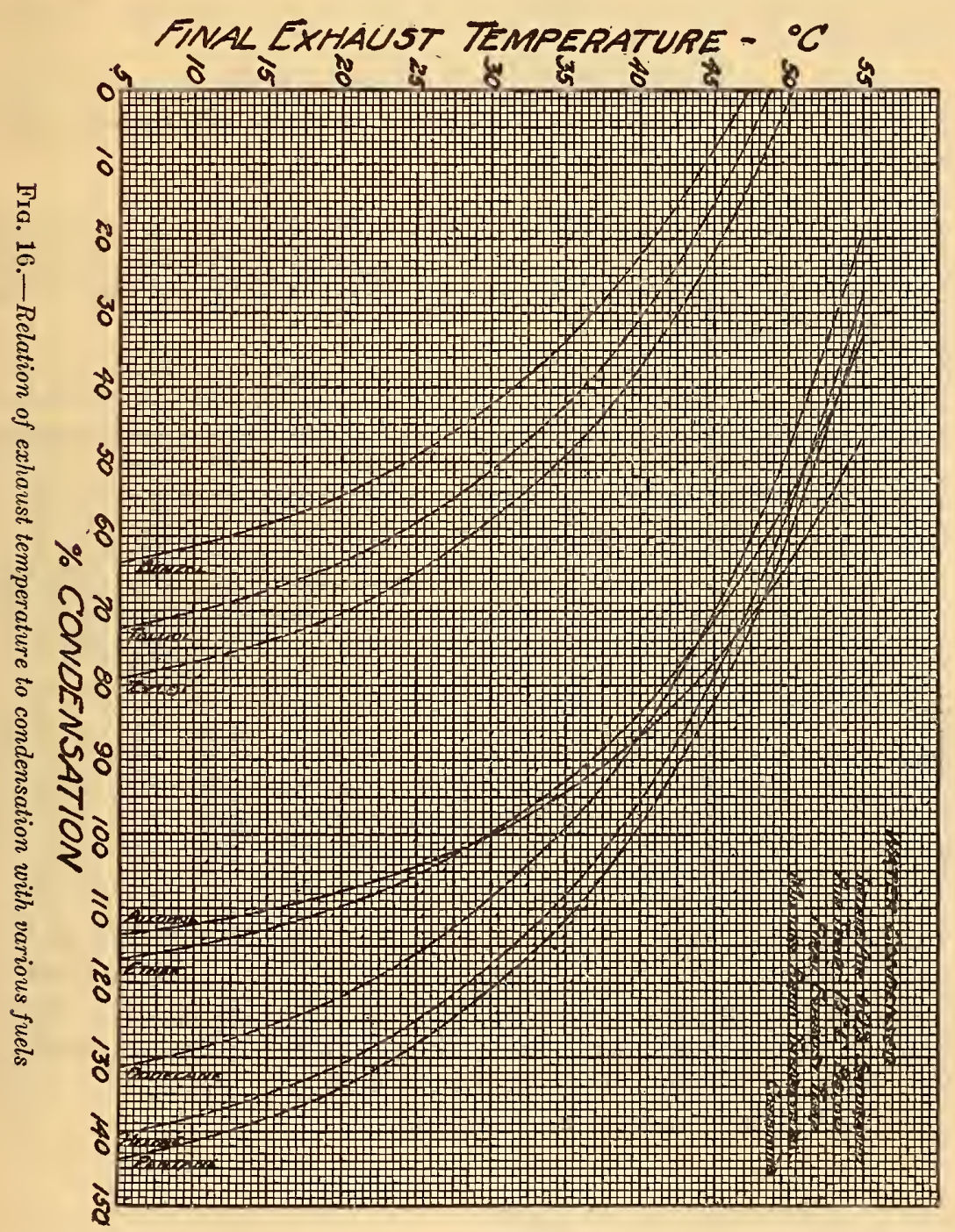

Taking pentane as an example, we have from its composition $\left(\mathrm{C}_{5} \mathrm{H}_{12}\right)$ the hydrogen and carbon content per pound 0.167 and 0.833 , respectively (see Table 2). Then, from the combining proportion of hydrogen and oxygen (1:8) the water of combustion will be nino times the weight of the hydrogen, or 1.500 pounds. 
Similarly, we know that the relation of the carbon dioxide to carbon is $\frac{44}{12}$, bringing the carbon dioxide produced to $\frac{44}{12} \times 0.833$, or 3.050 pounds. The oxygen required for combustion is then the difference between the weight of the fuel and that of the products of combustion.

$$
1.500+3.050-1.00=3.550 \text { pounds }
$$

Since the air is 77 per cent nitrogen by weight, the nitrogen content of the exhaust gas will be

$$
\frac{77}{23} \times 3.550=11.890 \text { pounds }
$$

and the total weight of air per pound of fuel will be the sum of the oxygen and nitrogen, or

$$
3.550+11.890=15.440 \text { pounds }
$$

TABLE 2.-Combustion data for liquid fuels assuming correct mixture ratio for complete combustion

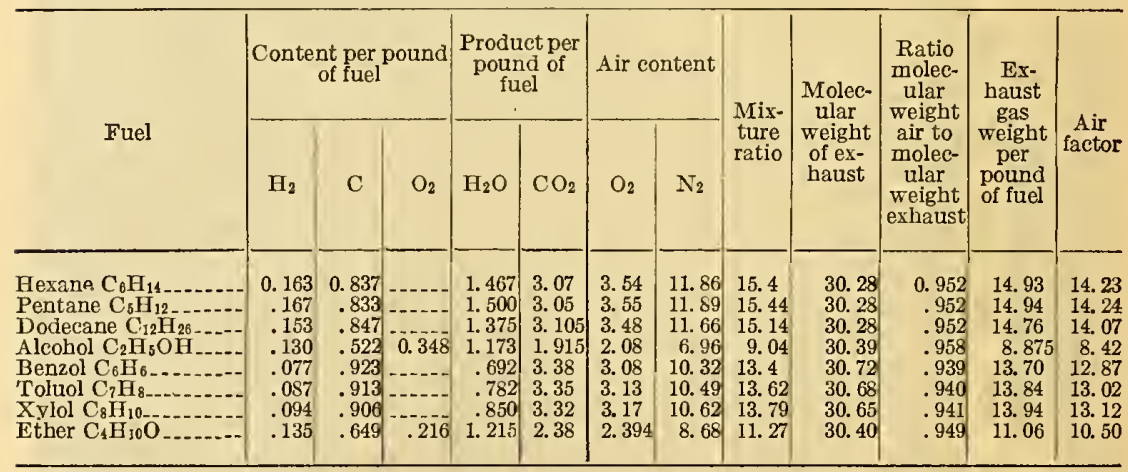

Expresscd as a ratio of weight, this is the correct combining air-fuel ratio. The weight of water vapor which will be taken up by a pound of dry gas at any temperature is proportional to the specific volume of the gas or inversely proportional to its density. For convenience, the molecular weight is substituted for density.

For air the mean molccular weight is

$$
\frac{100}{\frac{77}{28}+\frac{23}{32}}=28.84
$$

where 28 and 32 are the molecular wcights of nitrogen and oxygen, respectively. Similarly, the mean molecular weight of the exhaust gas products, exclusive of water, is

$$
\frac{3.050+11.890}{\frac{3.050}{44}+\frac{11.890}{28}}=30.28
$$


From these we obtain the ratio of mean molecular weights, and hence of the densities, of air and exhaust gas

$$
\frac{28.84}{30.28}=0.952
$$

which is also the inverse ratio of specific volumes, and hence the direct ratio of specific volumes of exhaust gas to air.

The total exhaust gas weight, exclusive of water, per pound of fuel is the sum of the carbon dioxide and nitrogen present, or

$$
3.050+11.890=14.940 \text { pounds }
$$

and the product of this with the ratio above gives the air factor shown in the last column of Table 2

$$
14.940 \times 0.952=14.240
$$

Since the air factor is the product of the ratio of specific volumes of exhaust gas and air and the weight of the exhaust gas (other than water vapor) per pound of fuel burned, the vapor content of the exhaust products leaving the condenser may be readily obtained by multiplying this factor by the weight of water necessary to saturate a pound of dry air at the same temperature and pressure. A physical representation of the air factor is the number of pounds of dry air which would be saturated by the quantity of water leaving the apparatus with the other exhaust products from 1 pound of fuel at the same temperature and pressure. For a constant fuel composition and mixture ratio the air factor does not change.

$T_{\mathrm{ABLE}}$ 3.-Pounds of water vapor leaving with exhaust gases per pound of fuel; relative humidity, 100 per cent

\begin{tabular}{l|c|c|c|c|c|c|c|c|c|c|c}
\hline $\begin{array}{l}\text { Exhaust temperature, } \\
{ }_{\mathrm{C}} \mathrm{C} .\end{array}$ & 5 & 10 & 15 & 20 & 25 & 30 & 35 & 40 & 45 & 50 & 55 \\
\hline Pounds moisture per \\
pound saturated air.-.
\end{tabular}

Referring now to Table 3 , the first line is the temperature of the exhaust gases issuing from the condenser. The second line is the moisture content of 1 pound of dry air saturated at this temperature and atmospheric pressure (Goodenough's tables). These values multiplied by the air factor from Table 2 give the water content of the outgoing gases per pound of fuel in each case.

The air temperatures in Table 4 are shown as $15^{\circ} \mathrm{C}$. lower than those of the final exhaust in Table 3 , complying with the assumption 
made. To ascertain the moisture entering with the air for each pound of fuel, it is only necessary to multiply the water per pound of air saturated by 0.60 (assumed relative humidity) and again multiply by the mixture ratio.

To find the water condensed (Table 5) at any temperature considered, the water content of the entering air (Table 4) is added to the water of combustion (Table 2), and the water content of the exhaust gas at the corresponding temperature is subtracted from this sum. The curves in Figure 17 are plotted from values recorded in Table 5 .

The water of combustion from pentane is 1.50 pounds (Table 2). Adding to this the water entering with the air at the lowest assumed temperature (Table 4), we have

$$
1.500+0.015=1.515 \text { pounds }
$$

Subtracting the water lost as vapor with the exhaust gas leaving the apparatus, we have

$$
1.515-0.077=1.438 \text { pound }
$$

which is the water condensed.

TABLE 4.--Pounds water vapor entering with air per pound of fuel; relative

\begin{tabular}{|c|c|c|c|c|c|c|c|c|c|c|c|}
\hline Air temperature, ${ }^{\circ} \mathrm{C}$. & -10 & -5 & 0 & 5 & 10 & 15 & 20 & 25 & 30 & 35 & 40 \\
\hline $\begin{array}{l}\text { Pounds moisture } \\
\text { per pound satu. } \\
\text { rated air......... }\end{array}$ & 0.001643 & 0.002553 & 0.003782 & 0.00542 & 0.00764 & 0.01068 & 0.01476 & 0.02017 & 0.02729 & 0.03662 & 0.04899 \\
\hline $\begin{array}{l}\text { Hexane } \\
\text { Pentane } \\
\text { Dodecane. } \\
\text { Alcohol } \\
\text { Benzol } \\
\text { Toluol } \\
\text { Xylol } \\
\text { Ether }\end{array}$ & $\begin{array}{l}.0152 \\
.0152 \\
.0149 \\
.0089 \\
.0132 \\
.0134 \\
.0136 \\
.0111\end{array}$ & $\begin{array}{l}.0236 \\
.0237 \\
.0232 \\
.0139 \\
.0205 \\
.0209 \\
.0211 \\
.0173\end{array}$ & $\begin{array}{l}.0350 \\
.0350 \\
.0344 \\
.0205 \\
.0304 \\
.0309 \\
.0313 \\
.0256\end{array}$ & $\begin{array}{l}.0501 \\
.0502 \\
.0493 \\
.0294 \\
.0436 \\
.0443 \\
.0449 \\
.0366\end{array}$ & $\begin{array}{l}.0706 \\
.0708 \\
.0694 \\
.0414 \\
.0614 \\
.0624 \\
.0632 \\
.0516\end{array}$ & $\begin{array}{l}.0987 \\
.0990 \\
.0971 \\
.0579 \\
.0859 \\
.0873 \\
.0884 \\
.0722\end{array}$ & $\begin{array}{l}.1364 \\
.1367 \\
.1341 \\
.0801 \\
.1186 \\
.1206 \\
.1222 \\
.0998\end{array}$ & $\begin{array}{l}.1863 \\
.1868 \\
.1833 \\
.1094 \\
.1621 \\
.1648 \\
.1669 \\
.1363\end{array}$ & $\begin{array}{l}.2520 \\
.2528 \\
.2480 \\
.1480 \\
.2193 \\
.2230 \\
.2258 \\
.1845\end{array}$ & $\begin{array}{l}.3383 \\
.3392 \\
.3327 \\
.1986 \\
.2944 \\
.2992 \\
.3031 \\
.2476\end{array}$ & $\begin{array}{l}.4527 \\
.4539 \\
.4453 \\
.2657 \\
.3938 \\
.4003 \\
.4054 \\
.3311\end{array}$ \\
\hline
\end{tabular}
humidity, 60 per cent

TABLE 5.-Pounds water condensed per pound of fuel, assuming complete combus-

\begin{tabular}{|c|c|c|c|c|c|c|c|c|c|c|c|c|}
\hline $\begin{array}{l}\text { Exhaust tem- } \\
\text { perature, }{ }^{\circ} \mathrm{C} \text {. }\end{array}$ & $\begin{array}{c}\text { Water } \\
\text { of com- } \\
\text { bus- } \\
\text { tion }\end{array}$ & 5 & 10 & 15 & 20 & 25 & 30 & 35 & 40 & 45 & 50 & 55 \\
\hline $\begin{array}{l}\text { Hexane } \\
\text { Pentane } \\
\text { Dodecane. } \\
\text { Alcohol } \\
\text { Benzol } \\
\text { Toluol } \\
\text { Xylol } \\
\text { Ether }\end{array}$ & $\begin{array}{r}1.467 \\
1.500 \\
1.375 \\
1.173 \\
.692 \\
.782 \\
.850 \\
1.215\end{array}$ & $\begin{array}{r}1.405 \\
1.438 \\
1.314 \\
1.136 \\
.636 \\
.725 \\
.792 \\
1.169\end{array}$ & $\begin{array}{r}1.382 \\
1.415 \\
1.291 \\
1.122 \\
.614 \\
.703 \\
.769 \\
1.152\end{array}$ & $\begin{array}{r}1.350 \\
1.383 \\
1.259 \\
1.103 \\
.585 \\
.674 \\
.741 \\
1.128\end{array}$ & $\begin{array}{r}1.309 \\
1.342 \\
1.218 \\
1.078 \\
.547 \\
.635 \\
.703 \\
1.097\end{array}$ & $\begin{array}{r}1.250 \\
1.283 \\
1.161 \\
1.044 \\
.494 \\
.582 \\
.649 \\
1.055\end{array}$ & $\begin{array}{l}1.174 \\
1.207 \\
1.085 \\
1.001 \\
.424 \\
.511 \\
.578 \\
.995\end{array}$ & $\begin{array}{r}1.082 \\
1.115 \\
.994 \\
.945 \\
.339 \\
.426 \\
.492 \\
.930\end{array}$ & $\begin{array}{l}0.956 \\
.989 \\
.869 \\
.870 \\
.224 \\
.309 \\
.374 \\
.837\end{array}$ & $\begin{array}{l}0.788 \\
.821 \\
.702 \\
.770 \\
.079 \\
.153 \\
.217 \\
.712\end{array}$ & $\begin{array}{r}0.565 \\
.598 \\
.481 \\
.637 \\
-.0- \\
.010 \\
.546\end{array}$ & $\begin{array}{r}0.275 \\
.307 \\
.193 \\
.465 \\
. \\
.332\end{array}$ \\
\hline
\end{tabular}
tion; relative humidity, 60 per cent

Since it is improbable that any fuel having exactly the composition of one of those shown in Figure 16 will ever be actually put into service use, this figure is supplemented by Figure 17, showing the final temperature to which the exhaust gas must be cooled in order 
to condense 1 pound of water per pound of any hydrocarbon fuel within the range of fuel composition apt to be encountered. This curve was derived by plotting the points at which the curves of Figure 16 cross the 100 per cent condensation line. In order to secure the points for the lower end of the curve, fuels having lower hydrogen content than the gasoline group were assumed. To find

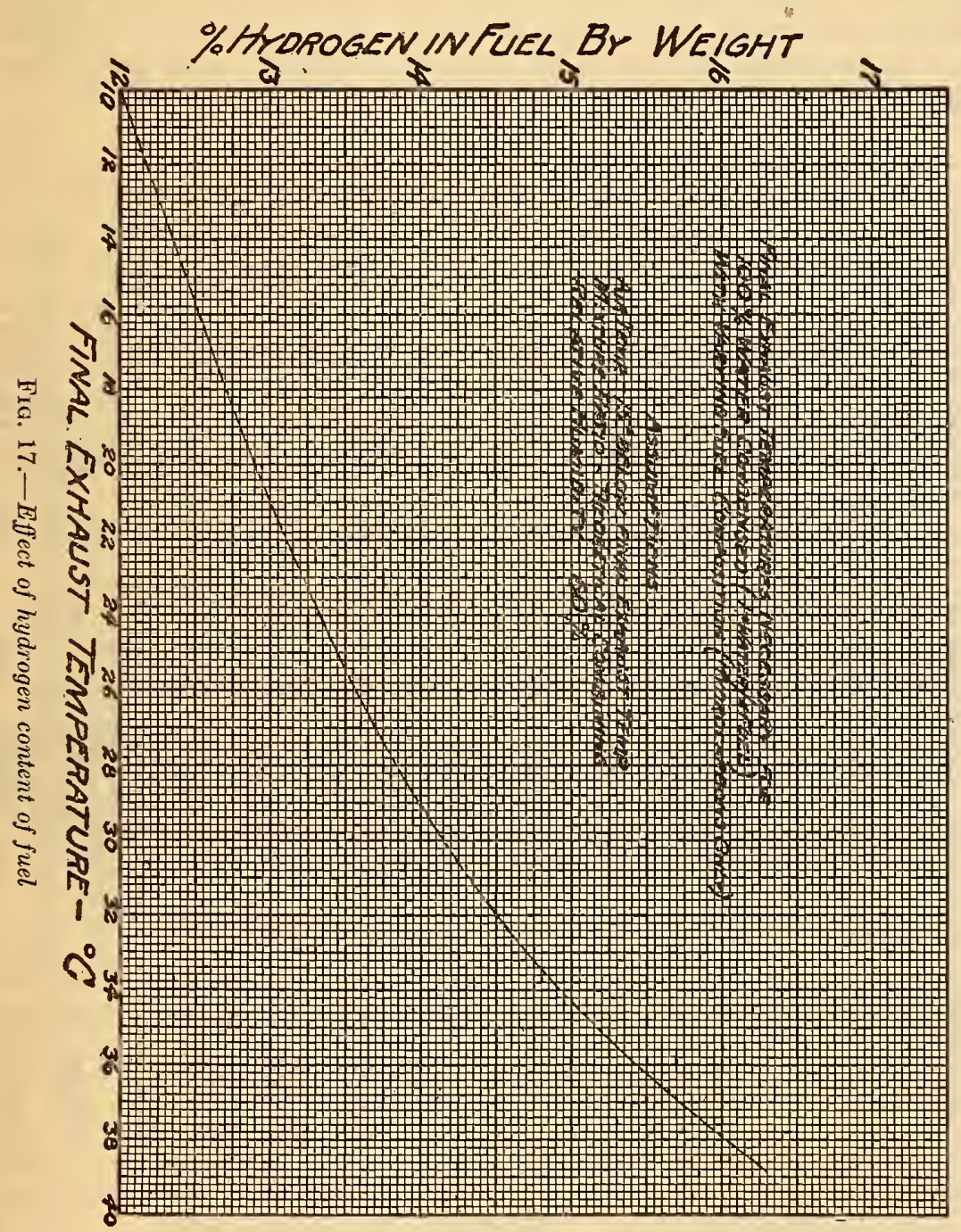

the required final temperature for 100 per cent condensation from any blend of hydrocarbon fuels, it is only necessary to know the hydrogen content of the mixture. The lower limit of the curve of Figure 17 represents a fuel blend of about 41 per cent benzol with a gasoline of 15 per cent hydrogen content. 


\section{MIXTURE RATIO}

All the curves shown thus far are based on the theoretical combining mixture ratios of air to fuel, which correspond to extremely lean carburetor settings and give the economy so vitally important in the operation of airships. Some multicylinder engines are unable to operate on mixtures quite as lean as those shown, but since the leaner mixtures are less advantageous as regards water recovery the curves are based on the worst expected condition and are on the safe side.

TABLE 6

\begin{tabular}{|c|c|c|c|c|c|c|c|c|c|}
\hline \multirow{2}{*}{ Mixture ratio $\frac{\text { air }}{\text { fuel }}$} & \multirow{2}{*}{$\begin{array}{l}\text { Oxygen } \\
\text { in air }\end{array}$} & \multirow{2}{*}{$\begin{array}{l}\text { Oxygen } \\
\text { in air } \\
\text { less } 1.2\end{array}$} & \multicolumn{3}{|c|}{$\begin{array}{l}\text { Exhaust gas } \\
\text { content }\end{array}$} & \multirow{2}{*}{$\begin{array}{c}\text { Molecu- } \\
\text { lar } \\
\text { weight } \\
\text { of ex- } \\
\text { haust } \\
\text { gas }\end{array}$} & \multirow{2}{*}{$\begin{array}{c}\text { Molecu- } \\
\text { lar } \\
\text { weight } \\
\text { ratio } \\
\text { air } \\
\text { exhaust }\end{array}$} & \multirow{2}{*}{$\begin{array}{l}\text { Weight } \\
\text { of } \\
\text { exhaust } \\
\text { gas per } \\
\text { pound } \\
\text { of fuel }\end{array}$} & \multirow{2}{*}{$\underset{\text { factor }}{\text { Air }}$} \\
\hline & & & $\mathrm{CO}_{2}$ & $\mathrm{~N}_{2}$ & $\mathrm{O}_{2}$ & & & & \\
\hline $\begin{array}{l}12 \ldots \\
13 \ldots \\
14 \ldots \\
15 . \\
16 .\end{array}$ & $\begin{array}{l}2.76 \\
2.99 \\
3.22 \\
3.45 \\
3.68\end{array}$ & $\begin{array}{l}1.56 \\
1.79 \\
2.02 \\
2.25 \\
2.48\end{array}$ & $\begin{array}{l}2.14 \\
2.46 \\
2.78 \\
3.09 \\
3.11\end{array}$ & $\begin{array}{r}9.24 \\
10.01 \\
10.78 \\
11.55 \\
12.32\end{array}$ & 0.22 & $\begin{array}{l}29.7 \\
30.18 \\
30.27 \\
30.32 \\
30.25\end{array}$ & $\begin{array}{r}0.972 \\
.956 \\
.953 \\
.952 \\
.954\end{array}$ & $\begin{array}{l}11.38 \\
12.47 \\
13.56 \\
14.64 \\
15.65\end{array}$ & $\begin{array}{l}11.05 \\
11.91 \\
12.91 \\
13.93 \\
14.92\end{array}$ \\
\hline
\end{tabular}

NoTE.-Gasoline assumed 15 per cent hydrogen; water produced $=0.15 \times 9=1.35 \# / \#$ fuel; necessary oxygen=1.35-0.15=1.2 pounds; molecular weight of air=28.84; air assumed 23 per cent oxygen, 77 per cent nitrogen.

TABLE 7.-Pounds water vapor lost with saturated exhaust gases per pound of gasoline

\begin{tabular}{|c|c|c|c|c|c|c|c|c|c|c|c|}
\hline Exhaust temperature, ${ }^{\circ} \mathrm{C}$. & 5 & 10 & 15 & 20 & 25 & 30 & 35 & 40 & 45 & 50 & 55 \\
\hline $\begin{array}{l}\text { Moisture per pound satu- } \\
\text { rated air. }\end{array}$ & 0.00542 & 0.00764 & 10.01068 & 0.01476 & 0.02017 & 0.02729 & 0.03662 & 0.04899 & 0.0654 & 0.0873 & 30.1156 \\
\hline $\begin{array}{l}\text { Mixture ratio: } \\
12 \\
134 \\
15 \\
16\end{array}$ & $\begin{array}{r}0.060 \\
.065 \\
.070 \\
.075 \\
.081\end{array}$ & $\begin{array}{r}0.084 \\
.091 \\
.099 \\
.106 \\
.114\end{array}$ & $\begin{array}{rr}4 & 0.118 \\
1 & .127 \\
& .138 \\
6 & .149 \\
& .159\end{array}$ & $\begin{array}{r}0.163 \\
.176 \\
.190 \\
.206 \\
.220\end{array}$ & \begin{tabular}{|c|}
0.223 \\
.240 \\
.260 \\
.281 \\
.301
\end{tabular} & $\begin{array}{r}0.302 \\
.326 \\
.352 \\
.380 \\
.407\end{array}$ & $\begin{array}{r}0.405 \\
.436 \\
.473 \\
.510 \\
.546\end{array}$ & $\begin{array}{r}0.542 \\
.584 \\
.633 \\
.683 \\
.730\end{array}$ & $\begin{array}{r}0.723 \\
.779 \\
.845 \\
.912 \\
.977\end{array}$ & $\begin{array}{l}0.965 \\
1.039 \\
1.127 \\
1.215 \\
1.301\end{array}$ & \begin{tabular}{l|l}
5 & 1.278 \\
9 & 1.377 \\
7 & 1.492 \\
5 & 1.612 \\
1 & 1.727
\end{tabular} \\
\hline
\end{tabular}

TABLE 8.-Pounds water vapor entering with air per pound of gasoline. Relative humidity, 60 per cent

\begin{tabular}{|c|c|c|c|c|c|c|c|c|c|c|c|}
\hline Air temperature, & -10 & -5 & 0 & 5 & 10 & 15 & 20 & 25 & 30 & 35 & 40 \\
\hline $\begin{array}{l}\text { Moisture per pound } \\
\text { saturated air }\end{array}$ & 0.001643 & 0.002553 & 0.003782 & 0.00542 & 0.00764 & 0.01068 & 0.01476 & 0.02017 & 0.02729 & 0.03662 & 0.04899 \\
\hline $\begin{array}{l}\text { Mixture ratio: } \\
12 \\
13 \\
15 \\
16\end{array}$ & $\begin{array}{r}0.012 \\
.013 \\
.014 \\
.015 \\
.016\end{array}$ & $\begin{array}{r}0.018 \\
.020 \\
.021 \\
.023 \\
.024\end{array}$ & $\begin{array}{r}0.027 \\
.030 \\
.032 \\
.034 \\
.036\end{array}$ & $\begin{array}{r}0.039 \\
.042 \\
.046 \\
.049 \\
.042 \\
\end{array}$ & \begin{tabular}{|r|} 
\\
2.055 \\
.060 \\
.064 \\
.069 \\
.073
\end{tabular} & $\begin{array}{l}0.077 \\
.083 \\
.090 \\
.096 \\
.103\end{array}$ & $\begin{array}{r}0.106 \\
.115 \\
.124 \\
.133 \\
.142\end{array}$ & $\begin{array}{r}0.145 \\
.157 \\
.169 \\
.181 \\
.194\end{array}$ & $\begin{array}{r}0.196 \\
.213 \\
.230 \\
.246 \\
.262\end{array}$ & $\begin{array}{r}0.263 \\
.286 \\
.307 \\
.329 \\
.351\end{array}$ & $\begin{array}{r}0.353 \\
.382 \\
.411 \\
.441 \\
.470\end{array}$ \\
\hline
\end{tabular}

TABLE 9.-Pounds water condensed per pound of gasoline. Relative humidity, 60 per cent

\begin{tabular}{|c|c|c|c|c|c|c|c|c|c|c|c|}
\hline $\begin{array}{c}\text { Final exhaust temper- } \\
\text { ature, }{ }^{\circ} \mathrm{C} .\end{array}$ & 5 & 10 & 15 & 20 & 25 & 30 & 35 & 40 & 45 & 50 & 55 \\
\hline $\begin{array}{l}\text { Mixture ratio: } \\
12 \\
13 \\
14 \\
15 \\
18\end{array}$ & $\begin{array}{l}1.302 \\
1.298 \\
1.294 \\
1.290 \\
1.285\end{array}$ & $\begin{array}{l}\text { 1. } 284 \\
\text { 1. } 279 \\
\text { 1. } 272 \\
\text { 1. } 267 \\
\text { 1. } 260\end{array}$ & $\begin{array}{l}1.259 \\
1.253 \\
1.244 \\
1.235 \\
1.227\end{array}$ & $\begin{array}{l}1.226 \\
1.216 \\
1.206 \\
1.193 \\
1.182\end{array}$ & $\begin{array}{l}\text { 1. } 182 \\
\text { 1. } 170 \\
\text { 1. } 154 \\
\text { 1. } 138 \\
\text { 1. } 122\end{array}$ & $\begin{array}{l}\text { 1. } 125 \\
\text { 1. } 107 \\
\text { 1. } 088 \\
\text { 1. } 066 \\
1.046\end{array}$ & $\begin{array}{r}1.051 \\
1.029 \\
1.001 \\
.973 \\
.946\end{array}$ & $\begin{array}{r}0.953 \\
.923 \\
.886 \\
.848 \\
.814\end{array}$ & $\begin{array}{l}0.823 \\
.784 \\
.735 \\
.684 \\
.635\end{array}$ & $\begin{array}{l}0.648 \\
.597 \\
.530 \\
.464 \\
.400\end{array}$ & $\begin{array}{l}0.425 \\
.355 \\
.269 \\
.179 \\
.093\end{array}$ \\
\hline
\end{tabular}


TABLE 10.-Pounds water condensed per pound of gasoline with dry and saturated air, mixture ratio, $13: 1$; gasoline, 15 per cent hydrogen

\begin{tabular}{|c|c|c|c|c|c|c|c|c|c|c|c|}
\hline $\begin{array}{c}\text { Final exhaust temper- } \\
\text { ature, }{ }^{\circ} \mathrm{C} \text {. }\end{array}$ & 5 & 10 & 15 & 20 & 25 & 30 & 35 & 40 & 45 & 50 & 55 \\
\hline Air temperature, ${ }^{\circ} \mathrm{C}$. & -10 & -5 & 0 & 5 & 10 & 15 & 20 & 25 & 30 & 35 & 40 \\
\hline $\begin{array}{l}\text { Water entering with } \\
\text { saturated air }\end{array}$ & 0.024 & 0.033 & 0.049 & 0.070 & 0.099 & 0.139 & 0.192 & 0.262 & 0.355 & 0.476 & 0.637 \\
\hline $\begin{array}{l}\text { Water lost with ex- } \\
\text { haust gas }\end{array}$ & .065 & .091 & .127 & .176 & .240 & .326 & .436 & .581 & .779 & 1.039 & 1.377 \\
\hline W ater condensed: & & & & & & & & & & & \\
\hline $\begin{array}{l}\text { Air saturated... } \\
\text { Air dry }\end{array}$ & $\begin{array}{l}1.309 \\
1.285\end{array}$ & $\begin{array}{l}\text { 1. } 292 \\
\text { 1. } 259\end{array}$ & $\begin{array}{l}\text { 1. } 272 \\
\text { 1. } 223\end{array}$ & $\begin{array}{l}1.244 \\
1.174\end{array}$ & $\begin{array}{l}\text { 1. } 209 \\
\text { 1. } 110\end{array}$ & $\begin{array}{l}1.163 \\
1.024\end{array}$ & $\begin{array}{r}1.106 \\
.914\end{array}$ & $\begin{array}{r}1.028 \\
.766\end{array}$ & $\begin{array}{l}.926 \\
.571\end{array}$ & $\begin{array}{l}.787 \\
.311\end{array}$ & .610 \\
\hline
\end{tabular}

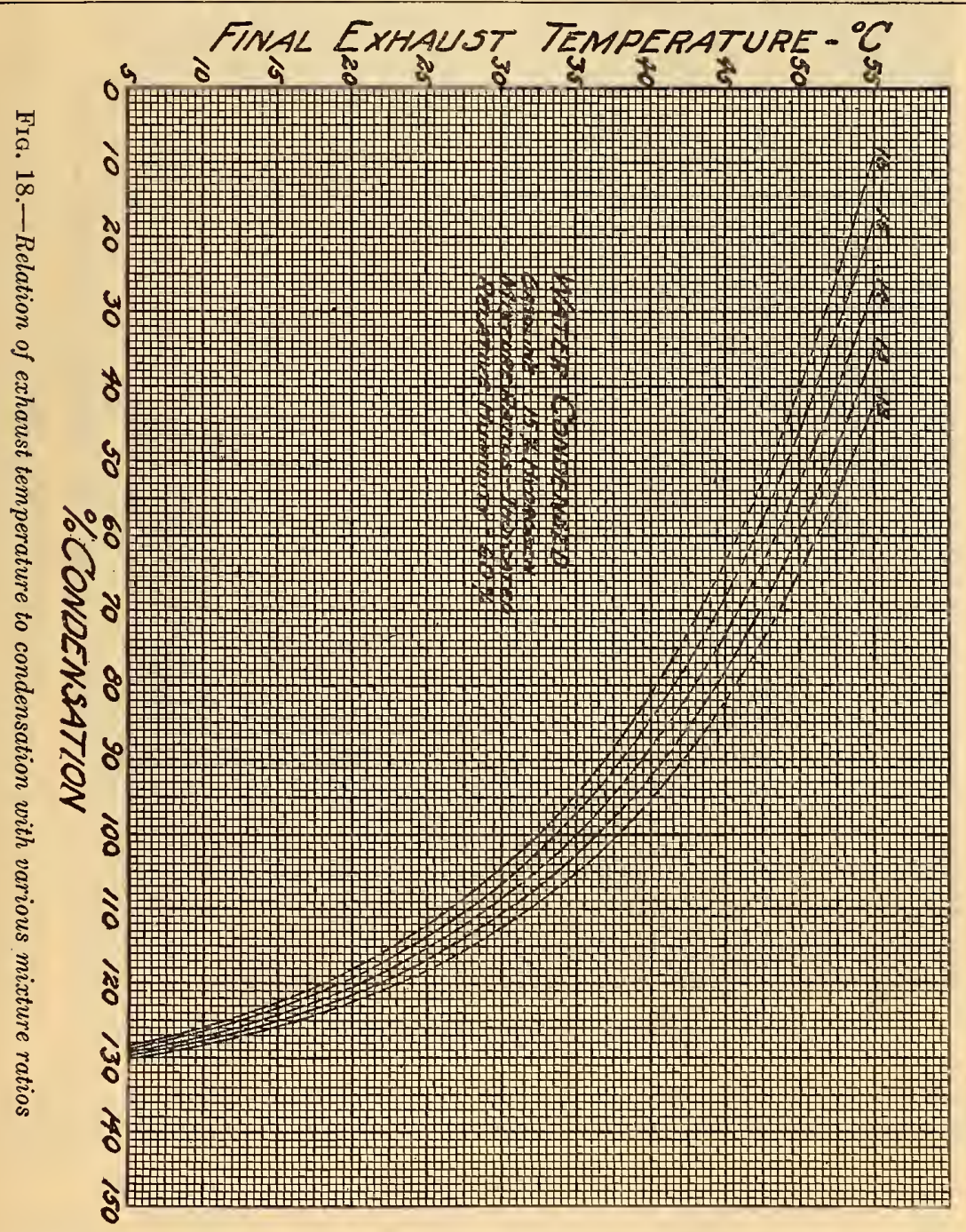

The effect of mixture ratio upon water condensed at various temperatures is shown in Figure 18. These curves wore computed in the same way as those of Figure 16, as represented by the compu- 
tation sheets, Tables $6,7,8$, and 9 . The fuel in this case was assumed to be gasoline having a 15 per cent hydrogen content, which closely approximates the fuel now in service use.

The final temperatures required for 100 per cent condensation (1 pound water per pound of fuel) using this fuel and the indicated

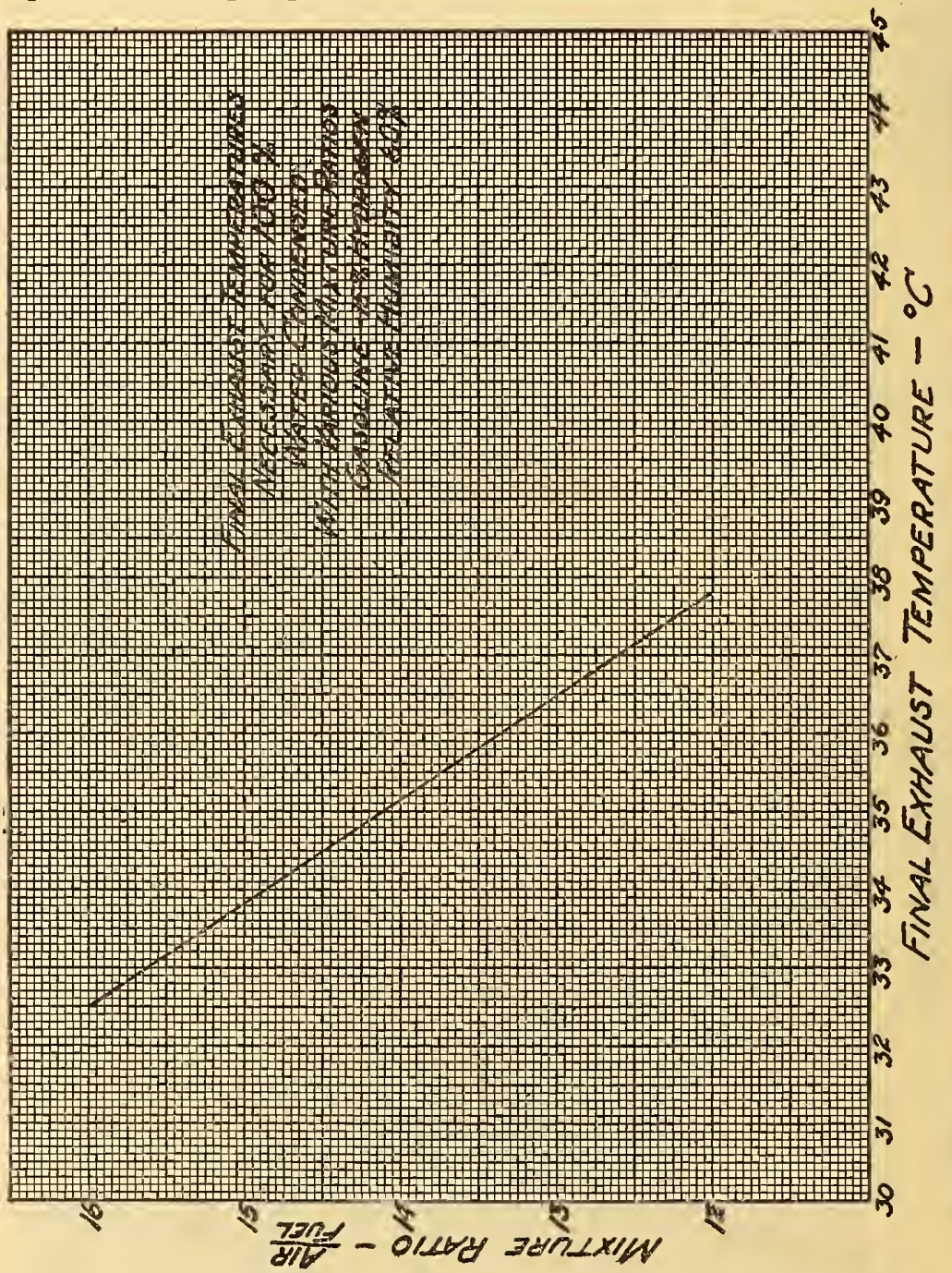

mixture ratios are shown in Figure 19, which is obtained by plotting the points where the curves of Figure 18 cross the 100 per cent line.

\section{HUMIDITY}

Since the humidity is uncontrolled, it may be that for special cases some figure other than the average one of 60 per cent may be applied. The curves of Figure 20 indicate the limits of the humidity 
range between zero and 100 per cent when using gasoline having a 15 per cent hydrogen content with a $13: 1$ air-fuel ratio. The data for these curves (Table 10) are largely obtained from the mixture ratio computations.

The points plotted on Figure 20 represent average values of the water collected in the endurance test of Model I condenser. It will

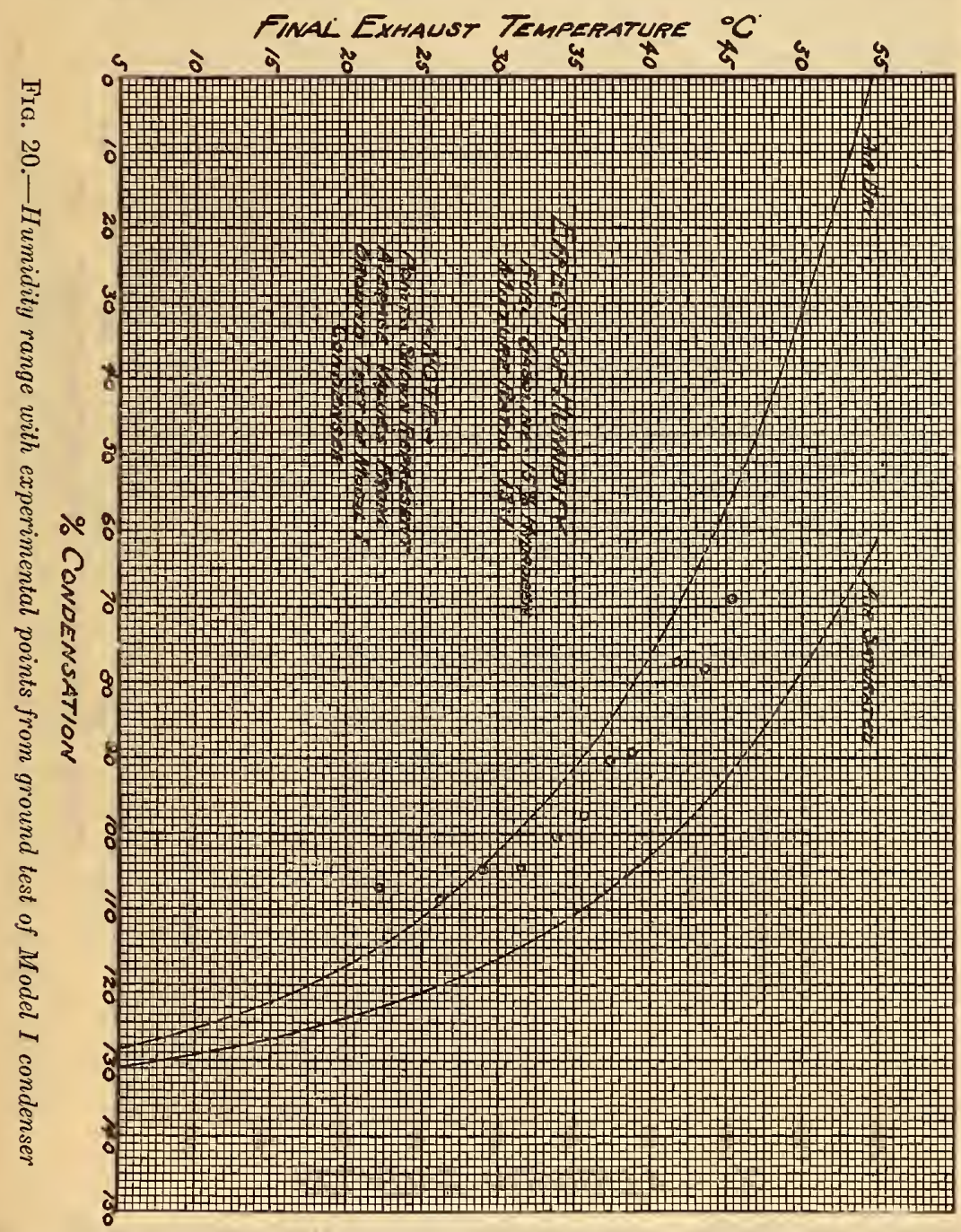

be noted that most of these points lie within the range indicated. Any leakage of exhaust gas or condensed water would tend to lower the apparent condensation, so that the assumption of 100 per cent separation is felt to be correct within reasonable limits.

The effect of humidity upon the final temperature necessary for 100 per cent water condensed is shown in Figure 21. This figure was 
obtained by plotting a series of curves similar to those of Figure 18 for several conditions of humidity and picking off the points of intersection with the 100 per cent condensing line as before.

It is obvious from the foregoing paragraphs and curves that it is a relatively simple matter to determine a desirable final exhaust

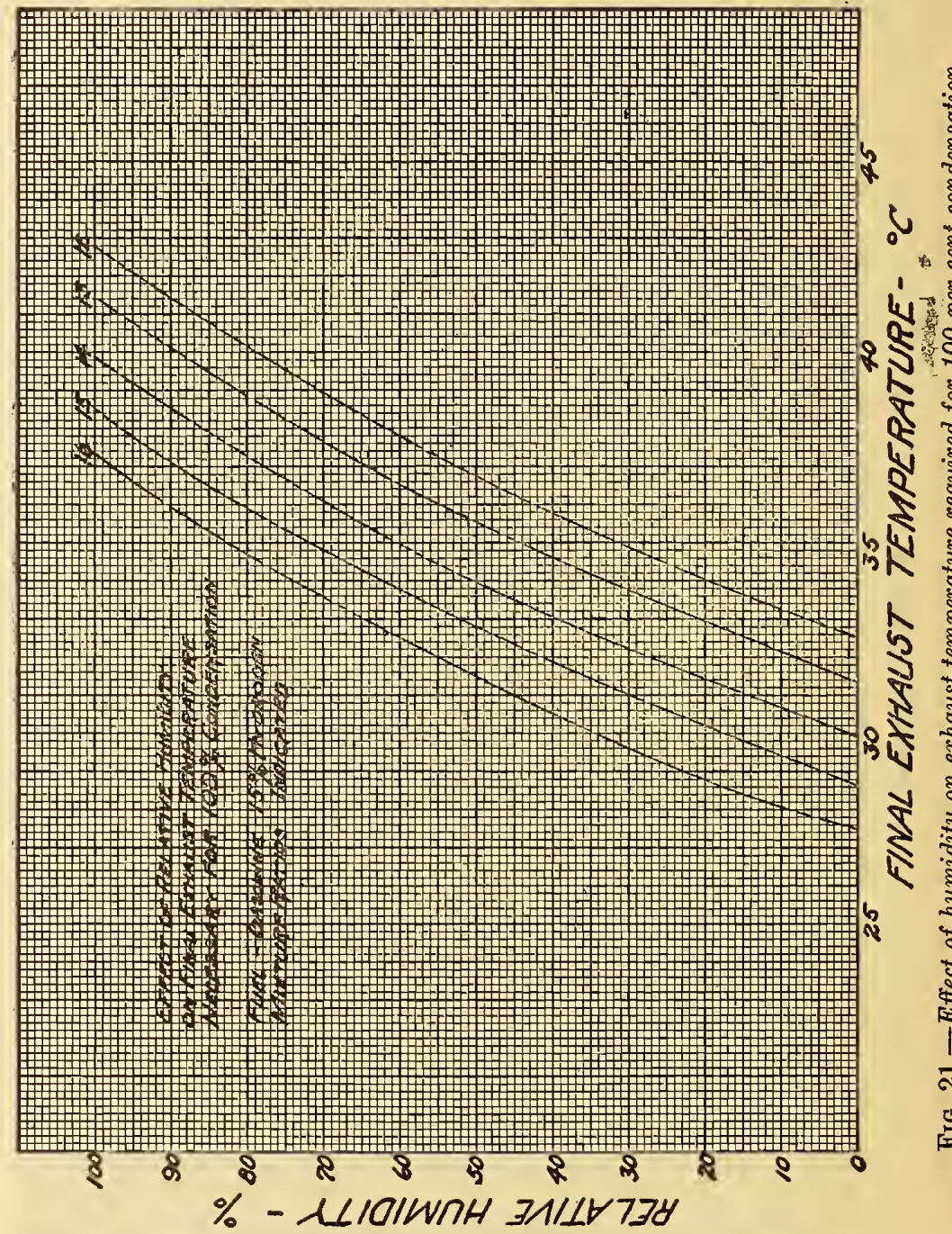

temperature, having assumed the kind of fuel, mixture ratio, air temperature, and relative humidity. From this point on the task is so to select and arrange the cooling system as to arrive at the desired final temperature.

\section{HEAT TRANSFER}

In an apparatus consisting of a bank of tubes parallel to the direction of flow of the cooling air stream it is evident that the conditions 
of heat transfer are different for those tubes at the center of the bank and those in the outer rows. For the purpose of design computations one tube at the center of the bank is considered. Inasmuch as the outer tubes are better cooled, this admittedly inaccurate method is at least on the safe side. The amount of cooling air flowing past each tube is determined by the spacing of the tubes.

The equations for heat transfer, which are the basis of the design of the exhaust cooling system, have been derived under the following assumptions: (a) The surface temperature of the pipe is the same inside and out at any given point in the length of the pipe and is uniform around the circumference; $(b)$ the cooling air flows with uniform velocity in a direction parallel to the axis of the pipe, is turbulent, and of temperature, density, pressure, and humidity characterizing normal atmospheric conditions.

In a given length of pipe, for steady conditions, the heat given up by the passing exhaust gas is equal to that taken up by the pipe wall, which is equal to that dissipated by the pipe wall and is equal, in turn, to that taken up by the external air stream. The loss of heat from the gas to the wall per element of length $d x$ at any point along the pipe is

$$
-M_{1} C_{1} \frac{d \theta_{1}}{d x} d x
$$

or

$$
-H_{1} \frac{d \theta_{1}}{d x} d x
$$

where

$M_{1}=$ mass of exhaust gas passing any point along the pipe, grams per second.

$C_{1}=$ specific heat of the gas at constant pressure, calories per gram per ${ }^{\circ} \mathrm{C}$.

$H_{1}=M_{1} C_{1}=$ heat capacity of the mass of exhaust gas which passes any point in unit time, calories per second per ${ }^{\circ} \mathrm{C}$.

$\theta_{1}=$ temperature of exhaust gas, ${ }^{\circ} \mathrm{C}$.

$x=$ coordinate along length of pipe, positive in the direction of exhaust gas flow.

$\frac{d \theta_{1}}{d x}=$ change in temperature per unit length of pipe.

$\frac{d \theta_{1}}{d x} d x=$ change in temperature per element of length.

The sign is negative, since the total heat of the exhaust decreases as $x$ increases. 
The heat taken up by the pipe wall per element of length is

where

$$
q_{1} p d x\left(\theta_{1}-\theta_{\mathrm{w}}\right)
$$

$q_{1}=$ coefficient of surface heat transfer between exhaust gas and pipe wall, calories per second per ${ }^{\circ} \mathrm{C}$. per $\mathrm{cm}^{2}$

$p=$ perimeter of pipe, $\mathrm{cm}$

$p d x=$ element of surface area, $\mathrm{cm}^{2}$

$\theta_{\mathrm{w}}=$ temperature of pipe wall, ${ }^{\circ} \mathrm{C}$.

Similarly, the heat dissipated by the pipe wall is

$$
q_{2} p d x\left(\theta_{\mathrm{w}}-\theta_{2}\right)
$$

and that heat taken up by the external air stream

where

$$
H_{2} \frac{d \theta_{2}}{d x} d x
$$

$q_{2}=$ coefficiert of surface heat transfer between pipe wall and air stream, calories per second per ${ }^{\circ} \mathrm{C}$, , per $\mathrm{cm}^{2}$

$\mathrm{H}_{2}=M_{2} \mathrm{C}_{2}=$ heat capacity of the mass of air stream which passes any point in unit time, calories per second per ${ }^{\circ} \mathrm{C}$.

$M_{2}=$ mass flow of air past any point along the pipe, grams per second.

$C_{2}=$ specific heat of air at constant pressure, calories per gram per ${ }^{\circ} \mathrm{C}$.

$\theta_{2}=$ temperature of air stream, ${ }^{\circ} \mathrm{C}$.

The conditions stated above, then, give the three equations

$$
\begin{gathered}
-H_{1} \frac{d \theta_{1}}{d x} d x=q_{1} p d x\left(\theta_{1}-\theta_{\mathrm{w}}\right) \\
H_{2} \frac{d \theta_{2}}{d x} d x=q_{2} p d x\left(\theta_{\mathrm{w}}-\theta_{2}\right) \\
q_{1}\left(\theta_{1}-\theta_{\mathrm{w}}\right)=q_{2}\left(\theta_{\mathrm{w}}-\theta_{2}\right)
\end{gathered}
$$

Combining these eliminates one variable, $\theta_{\mathrm{w}}$, and leaves two simultaneous differential equations in $\theta_{1}, \theta_{2}$, and $x$.

$$
\begin{gathered}
-\frac{H_{1}}{p q_{1}} \frac{d \theta_{1}}{d x}+\frac{H_{2}}{p q_{2}} \frac{d \theta_{2}}{d x}=\theta_{1}-\theta_{2} \\
H_{1} \frac{d \theta_{1}}{d x}+H_{2} \frac{d \theta_{2}}{d x}=0
\end{gathered}
$$

These can be solved to give $\theta_{1}$ and $\theta_{2}$ as functions of $x$

$$
\begin{aligned}
& \theta_{1}=A e^{\mathrm{nx}}+B \\
& \theta_{2}=-A \frac{H_{1}}{H_{2}} e^{\mathrm{nx}}+B
\end{aligned}
$$


where

$$
\begin{aligned}
& e=\text { base of natural logarithms } \\
& n=-p \frac{q_{1} q_{2}}{q_{1}+q_{2}}\left(\frac{1}{H_{1}}+\frac{1}{H_{2}}\right)
\end{aligned}
$$

$A$ and $B=$ constants of integratior

To eliminate these constants the following end conditions are applied:

For counterflow of exhaust gas and air

Where

$$
\left.\begin{array}{l}
\left.\begin{array}{l}
\theta_{1}=T_{\mathrm{a}} \\
\theta_{2}=t_{\mathrm{b}}
\end{array}\right\} \quad \text { when } x=0 \\
\theta_{1}=T_{\mathrm{b}} \\
\theta_{2}=t_{\mathrm{a}}
\end{array}\right\} \quad \text { when } x=L
$$

for parallel flow

$$
\left.\begin{array}{l}
\left.\begin{array}{l}
\theta_{1}=T_{\mathrm{a}} \\
\theta_{2}=t_{\mathrm{a}}
\end{array}\right\} \quad \text { when } x=0 \\
\theta_{1}=T_{\mathrm{b}} \\
\theta_{2}=t_{\mathrm{b}}
\end{array}\right\} \quad \text { when } x=L
$$

$T_{\mathrm{a}}=$ initial exhaust temperature, ${ }^{\circ} \mathrm{C}$.

$T_{\mathrm{b}}=$ final exhaust temperature, ${ }^{\circ} \mathrm{C}$.

$t_{\mathrm{a}}=$ initial air temperature, ${ }^{\circ} \mathrm{C}$.

$t_{\mathrm{b}}=$ final air temperature, ${ }^{\circ} \mathrm{C}$.

$L=$ length of pipe, $\mathrm{cm}$.

The resulting equations arranged in a form convenient for design work are

for counterflow

for parallel flow

$$
\log _{\mathrm{e}} \frac{T_{\mathrm{a}}-t_{\mathrm{b}}}{T_{\mathrm{b}}-t_{\mathrm{a}}}=p \frac{q_{1} q_{2}}{q_{1}+q_{2}}\left(\frac{1}{H_{1}}-\frac{1}{H_{2}}\right) L
$$

$$
\log _{\mathrm{e}} \frac{T_{\mathrm{a}}-t_{\mathrm{a}}}{T_{\mathrm{b}}-t_{\mathrm{b}}}=p \frac{q_{1} q_{2}}{q_{1}+q_{2}}\left(\frac{1}{H_{1}}+\frac{1}{H_{2}}\right) L
$$

The values for $q_{1}$ and $q_{2}$ are obtained from the Lanchester-Stanton relation ${ }^{4}$ combined with Lees' equation for skin friction.

in which

$$
q=C_{\mathrm{p}} m\left[0.0765\left(\frac{\mu}{m D}\right)^{0.35}+0.0009\right]
$$

$C_{\mathrm{p}}=$ specific heat at constant pressure

$\mu=$ viscosity, poises

$m=$ mass flow, grams per second per $\mathrm{cm}^{2}$

$D=$ diameter of tube, $\mathrm{cm}$

4 Great Britain Committee for Aeronautics Tech. Report $1912-13$ p. 45; B. S. Tech. Paper No. 211, p. 320 . 
In working toward a satisfactory heat-dissipating apparatus the first determination necessary is the total rate of mass flow of exhaust gas coming from the engine. This will be the product of the brake horsepower, the specific fuel consumption (pounds per brake horsepower hour), and the weight of mixture taken by the engine per pound of fuel, giving the mass flow in the pounds per hour. From consideration of equations (8) and (9), for maximum efficiency of heat transfer, it is desirable that the heat transfer coefficients, and hence the mass flows per unit cross-sectional area, be of the same order of magnitude inside and outside the tube. Then, having a known flying speed and air density, the resultant mass flow per unit cross-sectional area would be the rate of flow for exhaust gas most effective for cooling.

The density of the exhaust gas changes by a factor of three as the temperature drops from 650 to $30^{\circ} \mathrm{C}$., so that for a given mass flow the velocity at the hot end of the condenser is three times that at the cold end. Thus, for an air speed of 45 miles per hour, the average cruising speed of small airships now in service, the corresponding velocity at the hot end would be 135 miles per hour, which threatened difficulties due to back pressure. A compromise resulted in taking 0.017 pound per second per square inch (1.195 gs. per second per square centimeter) as the desirable mass flow inside the pipes.

The selection of the most advantageous size of tubes must of of necessity be a compromise between heat transfer efficiency and mechanical considerations. The effectiveness of the apparatus will be found (equation (5)) to be increased as the diameter of the tubes is decreased, whereas the smaller the tubes the greater will be the exhaust back pressure and liability to clogging and the less the mechanical strength of the tubes both as self-supporting beams and as long columns.

An indication of the relative resistance to flow with increase or decrease of pipe sizes may easily be obtained, but for the purposes of this work it is safe to let the limiting factor in reducing tube diameter be the mechanical strength necessary in a structure of the type contemplated. Soon after the beginning of design work on the full air-cooled type of water-recovery apparatus a tube of 1 inch diameter was assumed, and the strength of thin tubes of this size was computed. This choice of dimensions has since been vindicated by the ground and flying tests, since tubes of this diameter and the thinnest walls commercially obtainable have proven amply strong, while the back pressure is nearly at the allowable limit. In the theory and design sections of this paper, therefore, only tubing of circular section 1 inch in diameter is considered.

In solving equation (5) for $q_{2}$ the mass flow of air $M$ is determined by the air density, flying speed, and spacing and number of the 
tubes, while $D$ has a value also determined by the tube spacing. The diameter of a circle equivalent in area to the space included by four tubes was used as an approximation.

in which

$$
D=\sqrt{\frac{4 A B}{\pi}-d^{2}}
$$

$$
\begin{aligned}
& D=\text { equivalent diameter used in equation (5). } \\
& d=\text { diameter of tube. }
\end{aligned}
$$

$$
\left.\begin{array}{l}
A \\
B
\end{array}\right\}=\text { vertical and transverse spacing of tubes, respectively. }
$$

The specific heat of the exhaust gas is approximately constant for the range from 600 down to $55^{\circ},{ }^{5}$ the temperature at which condensation starts. Since this gas consists of approximately 10 per cent steam, for which $C_{\mathrm{p}}=0.45$, and 90 per cent other products of combustion, for which $C_{\mathrm{p}}=0.24$, the equivalent $C_{1}$ was taken as 0.26 .

For the range below $55^{\circ} \mathrm{C}$. the effective specific heat is very high due to the latent heat of condensation. This was approximately determined by computing the total heat of $1 \mathrm{~g}$ of the gas mixture at frequent temperature intervals below $55^{\circ} \mathrm{C}$. and finding the rate of change of total heat with temperature. This rate of change was taken as the effective specific heat with a mean value of 2.83 in the range 55 to $45^{\circ} \mathrm{C}$. and 1.92 in the range 45 to $35^{\circ} \mathrm{C}$., or 2.20 for the entire range 55 to $35^{\circ} \mathrm{C}$. The figure $45^{\circ} \mathrm{C}$. for the exhaust temperature at the end of the second condenser bank was secured by successive approximations and is used only to determine the effective specific heats over the ranges indicated. These values were checked by a more rigorous mathematical determination which can well be omitted here.

The viscosity of the gas changes considerably with temperature but an average value of $\mu$ over the range 600 to $55^{\circ} \mathrm{C}$. was taken as $2.4 \times 10^{-4}$ poise, the viscosity of air at $150^{\circ} \mathrm{C}$. For the range below $55^{\circ} \mathrm{C}$. it was assumed the effect of the condensing vapor was negligible and the value $2.0 \times 10^{-4}$ poises, the viscosity of air, was used. For the air flowing outside the tubes $\mu=1.85 \times 10^{-4}$.

Thus, we have constant values for the variables in equation (5), so that $q_{1}$ and $q_{2}$, and consequently $\frac{q_{1} q_{2}}{q_{1}+q_{2}}$, may be taken as constant for each range above and below the condensation point.

For a three-bank condenser of the general form of Model II it is not feasible to compute directly the necessary $L$ on account of the changing functions of the variables during parallel and counterflow as well as the change of $C_{\mathrm{p}}$ with temperature of the exhaust gas.

$\checkmark 55^{\circ} \mathrm{C}$. is an approximation. The temperature at which condensation starts changos somewhat with fuel composition, mirture, ratio, and humidity. 
The most convenient method is to assume an over-all length for the condenser and work through, using the equations given. It is, of course, necessary to measure or assume the temperature of the exhaust gas received by the condenser as well as the air temperature.

It will be found that there will be left two variables in each case, but that one of them can be eliminated by solving simultaneously with the equation expressing the fact that the heat lost by the exhaust is equal to the heat taken up by the air

$$
\left(T_{\mathrm{a}}-T_{\mathrm{b}}\right) H_{1}=\left(t_{\mathrm{b}}-t_{\mathrm{a}}\right) H_{2}
$$

Design computations will be taken up and examples given in another section of this paper.

Inasmuch as the heat to be abstracted from the exhaust gas varies with change in composition of the fuel, this total heat has been computed for three fuels-gasoline and two half-and-half mixtures of gasoline with benzol and alcohol, respectively. These latter represent two classes of antiknock fuel particularly suited to the requirements of high-compression engines. The change in total heat thus computed is equivalent to the heat abstracted in a constantpressure process between 650 and $32^{\circ} \mathrm{C}$. The exhaust gas is assumed to have been cooled to $650^{\circ} \mathrm{C}$. by the piping from the engines.

Under these conditions, assuming each fuel burned with a chemically correct mixture ratio, the heat abstracted is as follows:

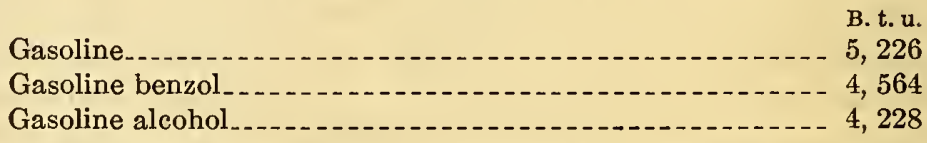

By using Figures 16 and 18 it will be found that at the final temperature of $32^{\circ} \mathrm{C}$. the water condensed from these three fuels will be 103.0, 71.3, and 98.0 per cent, respectively. Owing to the difference in mixture ratio, the same engine would burn about 25 per cent more of the alcohol mixture, so that the heat to be abstracted would be brought to about the same figure as that for gasoline alone. For 100 per cent condensation the exhaust from this mixture must be cooled to $30^{\circ} \mathrm{C}$.

The benzol blend, while having a low exhaust heat value, must be brought below $0^{\circ} \mathrm{C}$. before 100 per cent condensation can be obtained.

It is indicated, therefore, that blending of antiknock fuels for airship engines, especially for mixtures containing large proportions of the antiknocking component, should be accomplished by the use of alcohol rather than benzol. 


\section{Part III.-SAMPLE DESIGN}

For purposes of illustration the design of a condenser for a class $\mathrm{D}$ airship is taken up, assuming

$$
\begin{array}{ll}
\text { Maximum B. H. P. } & =300 . \\
& =\text { aviation gasoline. } \\
\text { Cruising speed } & =45 \text { miles per hour. } \\
\text { Mixture ratio } & =15: 1 .
\end{array}
$$

Referring now to Figure 18, the 15:1 mixture ratio curve crosses the 100 per cent condensation line at a temperature of $33.5^{\circ} \mathrm{C}$. This is the final temperature to which the exhaust gas must be cooled.

The total mass flow, based on the assumption of 0.50 pound fuel per brake horsepower hour, is

$$
0.50 \times(15.0+1.0) \times 300=2,400 \mathrm{lbs} . / \mathrm{hr} \text {. }
$$

For a speed of 45 miles per hour a mass flow of exhaust gas of 0.017 pound per second per square inch cross-sectional area is about right (see p. 32). Assuming round tubes of 1 inch diameter (p. 32), the cross-sectional area of each is $\frac{\pi}{4}$ square inches.

The mass flow per tube is

The total mass flow is

$$
\begin{aligned}
0.017 \times \frac{\pi}{4} & =0.0133 \mathrm{lb} . / \mathrm{sec} . \\
& =6.0 \mathrm{~g} / \mathrm{sec} .
\end{aligned}
$$

$$
\frac{2,400}{3,600}=0.667 \mathrm{lb} . / \mathrm{sec} \text {. }
$$

Hence, the number of tubes necessary is

$$
\frac{0.667}{0.0133}=50
$$

The rise in temperature of the cooling air must be kept small if the final temperature of the cooled exhaust is to be low. The mass flow of air, therefore, must be much greater than that of the exhaust gas.

For this reason the spacing of the Model II condenser was chosen as $2 \frac{1}{4}$ inches center to center of tubes in both directions. The crosssectional area of the air space under this condition is

$$
21 / 4 \times 21 / 4-\frac{\pi}{4}=4.277 \text { in. }^{2} / \text { tube }
$$


The mass flow of air is

in which

$$
\rho V a=M_{2}
$$

$$
\begin{aligned}
& \begin{array}{l}
\rho=\text { density }=0.0754 \mathrm{lb} . / \mathrm{ft}^{3}\left(750 \mathrm{~mm} \mathrm{Hg}, 15^{\circ} \mathrm{C} .\right) . \\
V=\text { velocity }=45 \mathrm{miles} \text { per hour }=66 \mathrm{ft} . / \mathrm{sec} .
\end{array} \\
& A=\text { cross-sectional area }\left\{\begin{array}{l}
=4.277 \mathrm{in.}^{2} \\
=0.0297 \mathrm{ft}^{2}
\end{array}\right. \\
& M_{\mathrm{r}}=0.0754 \times 66 \times 0.0297\left\{\begin{array}{l}
=0.148 \mathrm{lb} . / \mathrm{sec} . \\
=67 \mathrm{~g} / \mathrm{sec} .
\end{array}\right.
\end{aligned}
$$

From page 3 o

$$
\begin{aligned}
& C_{2}=0.24 \\
& C_{1}=0.26 \text { above } 55^{\circ} \mathrm{C} . \\
& C_{1}=2.83 \text { between } 55 \text { and } 45^{\circ} \mathrm{C} . \\
& C_{1}=1.92 \text { between } 45 \text { and } 35^{\circ} \mathrm{C} \text {. }
\end{aligned}
$$

Hence

and

$$
H_{2}=M M_{2} C_{2}=67 \times 0.24=16.08
$$

$$
\begin{aligned}
H_{1} & =6 \times 0.26=1.56 \text { above } 55^{\circ} \mathrm{C} . \\
& =6 \times 2.83=17.0 \text { between } 55 \text { and } 45^{\circ} \mathrm{C} . \\
& =6 \times 1.92=11.5 \text { between } 45 \text { and } 35^{\circ} \mathrm{C} .
\end{aligned}
$$

'The three values of $H_{1}$ apply, respectively, to the first and first part of the second section, the last part of the second, and all of the third section in a three-bank condenser, since these general temperature ranges prevail, as noted. Small departures from the indicated temperature ranges will not affect the values of $H_{1}$ to an appreciable extent, so that they may with reasonable accuracy be considered as constants.

Let us consider the condenser as divided into four sections of which 1 is the first bank, 2 is the first part of the second, 3 the last part of the second, and 4 the whole of the third bank. Then, since the first bank is in counterflow, the function of $H_{1}$ and $H_{2}$ is $\frac{1}{H_{1}}-\frac{1}{H_{2}}$, while the sign changes to plus for the second bank and back again to minus for the third. Calling this funcrion $H_{\mathrm{o}}$, we may compute the following values:

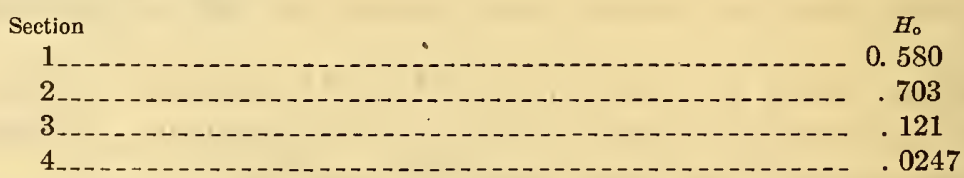

The coefficients of heat transfer $q_{1}$ and $q_{2}$ for this size pipe and spacing and the corresponding mass flow of gas and air per unit area are computed from equation (5). From pages 32 and 33 the values $C_{\mathbf{p}}, M, \mu$, and $D$, are as follows: 


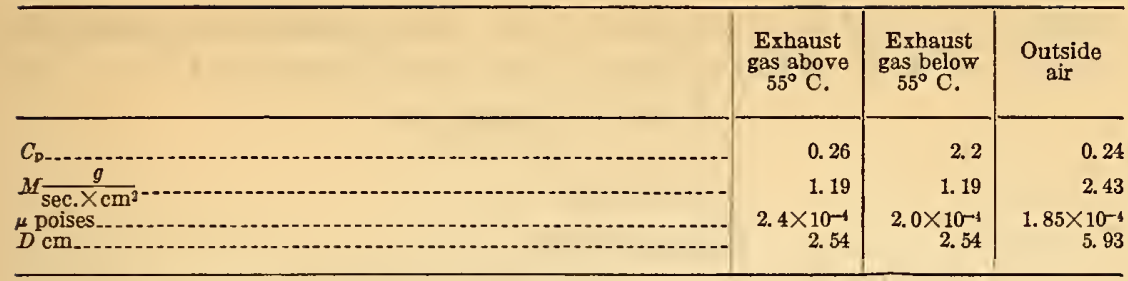

Substituting these values in equation (5)

$$
\begin{aligned}
& q_{1}=0.0012 \text { above } 55^{\circ} \mathrm{C} . \\
& q_{1}=0.0090 \text { below } 55^{\circ} \mathrm{C} . \\
& q_{2}=0.0014
\end{aligned}
$$

Hence, the values of $\frac{q_{1} q_{2}}{q_{1}+q_{2}}$ for the sections Nos. 1 to 4 above are as follows, $Q_{0}$ representing the function of $q_{1}$ and $q_{2}$

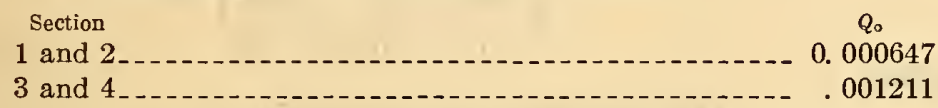

We may now combine all the functions of $q_{1}, q_{2}, H_{1}, H_{2}$, and $p$ in a single list of constants by multiplying together $H_{0}, Q_{0}$, and $p$. Call this constant $K$. The results follow:

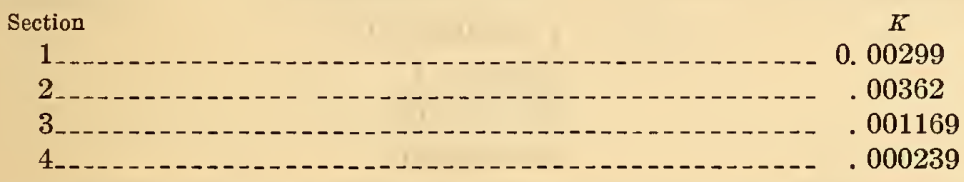

with the above values equations 3 and 4 take the form

and

$$
\log _{\mathrm{e}} \frac{T_{\mathrm{a}}-t_{\mathrm{b}}}{T_{\mathrm{b}}-t_{\mathrm{a}}}=K L \text { for counterflow }
$$

$$
\log _{\mathrm{e}} \frac{T_{\mathrm{a}}-t_{\mathrm{a}}}{T_{\mathrm{b}}-t_{\mathrm{b}}}=K L \text { for parallel flow. }
$$

For $T_{\mathrm{a}}$, the initial exhaust temperature at entrance to the condenser, $650^{\circ} \mathrm{C}$. may well be taken. This approximates the melting point of aluminum. For $t_{\mathrm{a}}$, the initial air temperature, $15^{\circ} \mathrm{C}$. is probably a fairly high figure. With these assumptions only two temperatures and the length remain to be determined. The only way to arrive at the desired temperature of $33.5^{\circ} \mathrm{C}$. for $T_{\mathrm{b}}$ is to assume a length and apply the equations for each section, finding the final $T_{\mathrm{b}}$ for the last section. The length of the condenser may then be increased or decreased, according as the final temperature of exhaust is too high or too low.

For this purpose let us assume an effective over-all length of 20 feet, making a total length of 60 feet in three banks, of which the 
second is parallel flow. Keeping to the same designation of the four sections involved in the calculation, we have for section 1

$$
\begin{aligned}
& L=20 \text { feet }=610 \mathrm{~cm} \\
& T_{\mathrm{a}}=650^{\circ} \mathrm{C} . \\
& t_{\mathrm{a}}=15^{\circ} \mathrm{C} . \\
& K=0.00299 \\
& \log _{\mathrm{e}} \frac{T_{\mathrm{a}}-t_{\mathrm{b}}}{T_{\mathrm{b}}-t_{\mathrm{a}}}=K L= 0.00299 \times 610=1.824=\log _{\mathrm{e}} 6.20 \\
& \frac{650-t_{\mathrm{b}}}{T_{\mathrm{b}}-15}=6.20 \\
& t_{\mathrm{b}}=650-6.20 T_{\mathrm{b}}+93.0=743.0-6.20 T_{\mathrm{b}}
\end{aligned}
$$

Simultaneously

or

$$
\left(T_{\mathrm{a}}-T_{\mathrm{b}}\right) H_{1}=\left(t_{\mathrm{b}}-t_{\mathrm{a}}\right) H_{2}
$$

$$
\begin{aligned}
\left(650-T_{\mathrm{b}}\right) 1.56 & =\left(t_{\mathrm{b}}-15\right) 16.08 \\
t_{\mathrm{b}} & =15+63.1-0.0971 T_{\mathrm{b}} \\
& =78.1-0.0971 T_{\mathrm{b}}
\end{aligned}
$$

Therefore,

$$
\begin{aligned}
743.0-6.20 & T_{\mathrm{b}}=78.1-0.0971 T_{\mathrm{b}} \\
6.103 & T_{\mathrm{b}}=664.9 \\
& T_{\mathrm{b}}=108.9^{\circ} \mathrm{C} .
\end{aligned}
$$

The conditions at section 2 are thus determined:

$$
\begin{aligned}
T_{\mathrm{s}} & =108.9^{\circ} \mathrm{C} . \\
t_{\mathrm{a}} & =15^{\circ} \mathrm{C} . \\
T_{\mathrm{b}} & =55^{\circ} \mathrm{C} . \\
K & =0.00262
\end{aligned}
$$

Since parallel flow now prevails, the main equation becomes

$$
\begin{gathered}
\log _{\mathrm{e}} \frac{T_{\mathrm{a}}-t_{\mathrm{a}}}{T_{\mathrm{b}}-t_{\mathrm{b}}}=K L=0.00362 L \\
\log _{\mathrm{e}} \frac{108.9-15}{55-t_{\mathrm{b}}}=0.00362 L \\
\log _{\mathrm{e}} \frac{93.9}{55-t_{\mathrm{b}}}=0.00362 L
\end{gathered}
$$

and also $\left(T_{\mathrm{a}}-T_{\mathrm{b}}\right) H_{1}=\left(t_{\mathrm{b}}-t_{\mathrm{a}}\right) H_{2}$

$$
\begin{gathered}
(108.9-55) 1.56=\left(t_{\mathrm{b}}-15\right) 16.08 \\
t_{\mathrm{b}}=15+\frac{1.56}{16.08}(108.9-55) \\
=15+5.23=20.23
\end{gathered}
$$

substituting above for $t_{\mathrm{b}}$

$$
\begin{gathered}
\log _{\ominus} \frac{93.9}{55-20.23}=0.00362 L=\log _{\ominus} \frac{93.9}{34.77} \\
\log _{e} 2.703=0.994 \\
L=\frac{0.994}{0.00362}=275 \mathrm{~cm}
\end{gathered}
$$


The length for section 3 will be the difference between 610 and $275 \mathrm{~cm}$. The conditions at this section are then

$$
\begin{aligned}
T_{\mathrm{a}} & =55^{\circ} \mathrm{C} . \\
t_{\mathrm{a}} & =20.23 \\
L & =610-275=335 \mathrm{~cm} \\
K & =0.001169
\end{aligned}
$$

The flow is still parallel as in section 2, so that

$$
\log _{\mathrm{e}} \frac{T_{\mathrm{a}}-t_{\mathrm{a}}}{T_{\mathrm{b}}-t_{\mathrm{b}}}=K L
$$

$$
\log _{\mathrm{e}} \frac{55-20.23}{T_{\mathrm{b}}-t_{\mathrm{b}}}=0.001169 \times 335=0.392^{\circ}=\log _{\odot} 1.480
$$

$$
\frac{34.77}{T_{\mathrm{b}}-t_{\mathrm{b}}}=1.480
$$

Simultaneously,

$$
\begin{aligned}
\left(T_{\mathrm{a}}-T_{\mathrm{b}}\right) H_{\mathrm{1}} & =\left(t_{\mathrm{b}}-t_{\mathrm{a}}\right) H_{2} \\
\left(55-T_{\mathrm{b}}\right) 17 & =\left(t_{\mathrm{b}}-20.23\right) 16.08 \\
t_{\mathrm{b}} & =20.23+58.1-1.056 T_{\mathrm{b}}
\end{aligned}
$$

Dropping $t_{\mathrm{b}}$

$$
\begin{aligned}
T_{\mathrm{b}}-23.50 & =78.33-1.056 T_{\mathrm{b}} \\
2.056 T_{\mathrm{b}} & =101.83 \\
\dot{T}_{\mathrm{b}} & =49.6
\end{aligned}
$$

The conditions for section 4 are now determined as

$$
\begin{aligned}
T_{\mathrm{a}} & =49.6^{\circ} \mathrm{C} . \\
t_{\mathrm{a}} & =15^{\circ} \mathrm{C} . \\
L & =610 \mathrm{~cm} \\
K & =0.00239
\end{aligned}
$$

The flow is now changed again to counterflow, so that

Simultaneously,

$$
\begin{aligned}
\log _{\mathrm{e}} \frac{T_{\mathrm{a}}-t_{\mathrm{b}}}{T_{\mathrm{b}}-t_{\mathrm{a}}}=K L \\
\log _{\mathrm{e}} \frac{49.6-t_{\mathrm{b}}}{T_{\mathrm{b}}-15}=0.000239 \times 610=0.1458 \\
=\log _{\odot} 1.157 \\
t_{\mathrm{b}}=49.6-1.157 T_{\mathrm{b}}+17.35 \\
=66.95-1.157 T_{\mathrm{b}}
\end{aligned}
$$

$$
\begin{aligned}
\left(T_{\mathrm{a}}-T_{\mathrm{b}}\right) H_{1} & =\left(t_{\mathrm{b}}-t_{\mathrm{a}}\right) H_{2} \\
\left(49.6-T_{\mathrm{b}}\right) 11.5 & =\left(t_{\mathrm{b}}-15\right) 16.08 \\
t_{\mathrm{b}} & =15+35.5-0.716 T_{\mathrm{b}} \\
& =50.5-0.716 T_{\mathrm{b}}
\end{aligned}
$$


Hence,

$$
\begin{aligned}
66.95-1.157 & T_{\mathrm{b}}=50.5-0.716 T_{\mathrm{b}} \\
0.441 & T_{\mathrm{b}}=16.45 \\
& T_{\mathrm{b}}=37.3^{\circ} \mathrm{C} .
\end{aligned}
$$

This temperature is somewhat higher than that required for 100 per cent condensation under the assumed conditions, but the difference is no greater than the probable error in the assumed values used in computing the heat transfer. The fact that the cooling surface of the cast aluminum headers has not been taken into consideration also makes probable a somewhat better performance than that indicated by the computations.

It is not contended that a three-bank condenser of the same type as Models I and II is the ultimate solution of the problem of exhaust heat transfer. When the construction and arrangement of the airship permit, it may be possible to secure better results by using fewer banks and a greater over-all length, or vice versa. It may be found advisable in order to facilitate drainage to change the position so that the long dimension of cross section is vertical; as if, for example, it were placed against the side wall of the car of a D or C class ship.

It is by no means certain that the use of the same number of tubes in each bank is desirable for the best condition of heat exchange. It is suggested that valuable data might be made available by a mathematical comparison of the present type exemplified by Model II, and one in which the number of tubes in the first bank is increased by one-third or one-half and the number in the last bank correspondingly decreased. This would give a more uniform velocity of exhaust gas and might on this account increase the over-all efficiency of the unit. For the purpose of designing apparatus similar to the two condensers already built the computations have been worked out between wide limits of air speed, condenser length, and initial exhaust temperature. The final temperature of the exhaust necessary for 100 per cent condensation was taken as $32^{\circ} \mathrm{C}$., which allows a margin of safety of $1.5^{\circ} \mathrm{C}$. The curves are shown on Figure 22, which requires little explanation.

Assuming the same conditions used in the design computations just preceding-that is, an entrance exhaust gas temperature of $650^{\circ} \mathrm{C}$., air temperature $15^{\circ} \mathrm{C}$., and air speed 45 miles per hour-the required length is readily determined. It is only necessary to project the horizontal line of $15^{\circ} \mathrm{C}$. air temperature to its intersection with the second curve of the lowest group and then to read the required length on the scale at the bottom of the sheet. The value thus obtained is 



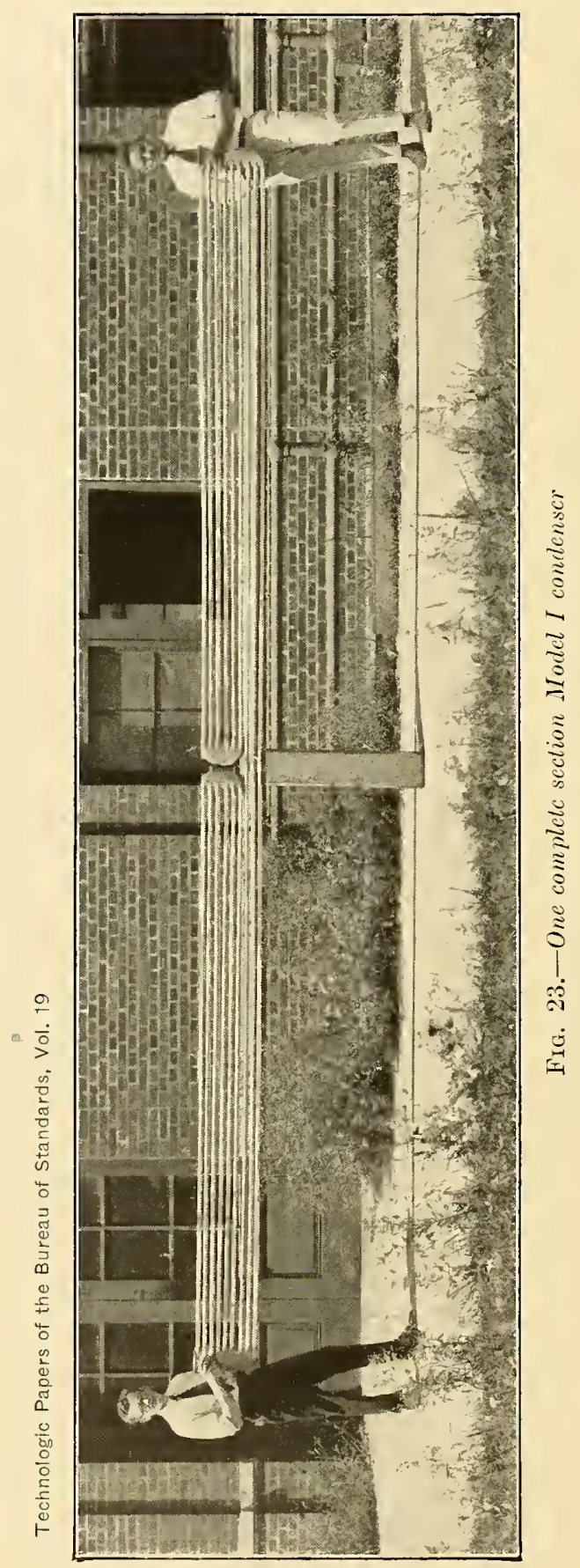


approximately 25 feet, which is somewhat longer than the value computed. It is to be remembered that the final exhaust temperature in this case $\left(32^{\circ}\right)$ is some $5^{\circ} \mathrm{C}$. lower than that computed for the 20foot condenser, and that the cooling over the range of temperature

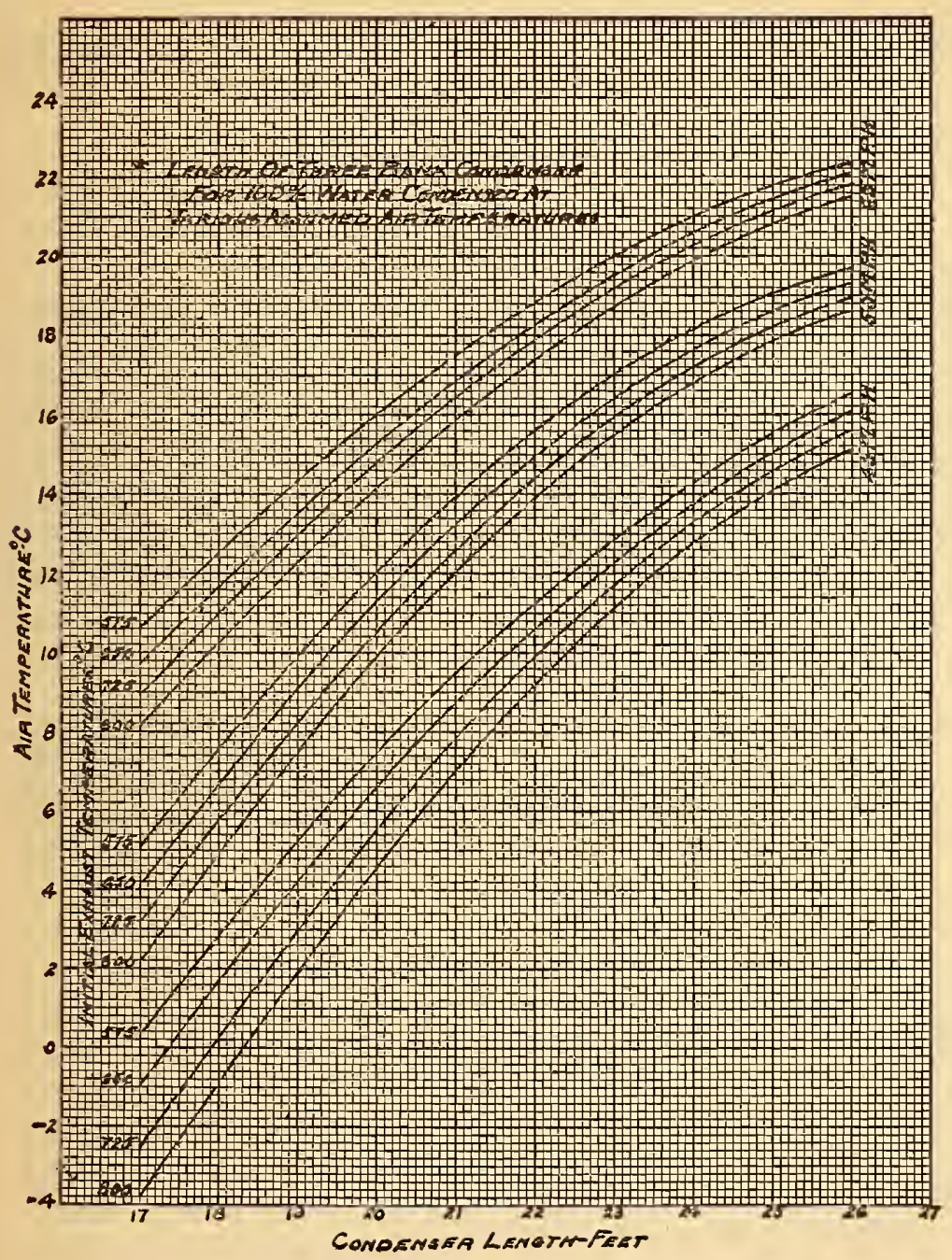

FIG. 22.-Design curves for condenser length, assuming 1 tube for 6 brake horsepower

covered by this difference is extremely ineffective, owing to the small temperature head between the exhaust gas and the cooling air stream.

Washington, April 11, 1925. 